\title{
Untangling locality and orientation constraints in the L2 acquisition of anaphoric binding: a feature-based approach ${ }^{1}$
}

\author{
Laura Domínguez, Glyn Hicks, Hee-Jeong Song \\ University of Southampton
}

\begin{abstract}
This study offers a Minimalist analysis of the L2 acquisition of binding properties whereby crosslinguistic differences arise from the interaction of anaphoric feature specifications and operations of the computational system (Reuland 2001, 2011; Hicks 2009). This analysis attributes difficulties in the L2 acquisition of locality and orientation properties in binding to problems reanalysing the features responsible for reflexivisation in the target language. Such an approach is shown to predict, in contrast to previous accounts, that if the locality and orientation behaviour of English reflexives arise due to syntactic operations on their features (Agree), acquisition of locality cannot be achieved unless orientation is also acquired; a picture-verification task completed by 70 Korean L2 speakers of English fully bears out this prediction. We show that for independent reasons, Korean speakers could still behave apparently nativelike for locality (by means of L1 transfer), but not for orientation. Crucially, this analysis can explain how two properties traditionally subsumed under the same UG principle can appear to pose different learning difficulties to L2 speakers.
\end{abstract}

\section{Towards a Minimalist account of anaphoric binding: setting the scene}

In its original form, the 'canonical' or 'classical' Binding Theory (BT) (Chomsky 1981, 1986) was conceived as a module of the grammar comprising a defined set of syntactic principles represented in all languages. These principles, or 'binding conditions', were claimed to be able to explain the distribution and referential dependencies of anaphors and pronominals across languages. Binding Condition A, which states that an anaphor must be locally bound by a c-commanding antecedent, accounted for the syntactic environments in which anaphors can establish a coreferential relation with their antecedents. The condition is satisfied in (1a), but not in (1b) because the anaphor himself cannot be bound by the antecedent John; only the 'closer' subject Mary is present within the local binding domain:

\footnotetext{
${ }^{1}$ The authors are listed alphabetically. We would like to thank audiences at our talks in Autumn 2011 at BUCLD 36, GALA (Thessaloniki) and LAGB (Manchester), as well as three anonymous Language Acquisition reviewers whose comments led to substantial improvements. Special thanks to Kook-Hee Gil for pointing out some aspects of reflexive binding in Korean which are particularly relevant for this study. Errors, oversights and any other shortcomings remain our own.
} 
1) a. $J_{o h n}$ poked himself ${ }_{i}$ with a stick

b. ${ }^{*} \mathrm{John}_{\mathrm{i}}$ expected [Mary to poke himself $\mathrm{i}_{\mathrm{i}}$ with a stick]

The development of a UG-based BT was crucial in supporting the classical generativist model of language acquisition, as binding conditions did not have to be learnt by children. It was argued that BT could not be fully acquired on the basis of positive evidence alone and that "children do not add the Binding Theory to a more permissive system of generating sound/meaning pairs. Rather, the Binding Theory reflects innate features of human grammars; children never consider the possibilities it excludes. For once considered, ruling out such possibilities would require (correcting) evidence that children do not typically have" (Crain \& Pietroski 2001:152). Access to principles of UG was thus necessary to explain how children could attain an adult grammar in this domain. BT has subsequently been of central importance in developing our understanding of the specific role played by UG in the acquisition of non-native grammars (e.g. Finer \& Broselow 1986; Hirakawa 1990; Finer 1991; Bennett 1994; Eckman 1994; Lakshmanan \& Teranishi 1994; Thomas 1989, 1991, 1995; White 1995; Wakabayashi 1996; Bennett \& Progovac 1998; MacLaughlin 1998; Yip \& Tang 1998; Yuan 1998; Ying 1999; Jiang 2009).

Binding theory can thus be considered as one of the major achievements of Principles and Parameters theory that has also successfully contributed to the development of generative SLA theorising. However, from the perspective of syntactic theory, the intensive research into binding within - and beyond - the Government and Binding (GB) era has illuminated several crucial weaknesses of the original formulation of BT. From an empirical perspective, the earliest research in the wake of Chomsky (1981) soon showed that even for an intensely studied language such as English, there are certain contexts where the occurrence of reflexives is very hard to explain by the mechanisms made available by the canonical BT. ${ }^{2}$ More significantly though, the binding conditions subsumed under BT were found not to be capable of adequately explaining straightforward crosslinguistic variation regarding the behaviour of reflexives. Manzini \& Wexler's (1987) extension of the canonical model to accommodate language-specific behaviours concerning binding domains (determined by the particular choice of settings associated with corresponding parameters) sought to resolve this

\footnotetext{
${ }^{2}$ Some of the early problems centred on the fact that in certain contexts the expected complementary distribution of anaphors and pronouns breaks down (Huang 1983; Lebeaux 1983), resulting in the partially successful developments to the theory in Chomsky (1986).
} 
but did not fully succeed in its aim. For example, it is not the case that the particular binding domain value selected is a property of a specific language; rather, as noted as early as Faltz (1977), different anaphors and pronouns themselves (often within a single language) take different binding domains. Thus, unlike the standard GB view of parameters as a one-time selection for a given language, the parameter values for Manzini \& Wexler's Governing Category parameter were selected for individual lexical items. The canonical BT's initial focus on English resulted in another important oversight which had also been noted by Faltz (1977): cross-linguistically, the behaviour of binding varies not only according to the size of the domain in which an anaphor finds an antecedent, but also according to whether the anaphor must be oriented to a subject antecedent or not. This was again partially addressed by Manzini \& Wexler through the addition of a Proper Antecedent parameter, although significant interactions between its values and those of the Governing Category parameter (see relevant discussion in section 2.1) were not formalised within their framework. Thus, surveying the classical binding conditions, Reuland (2005:579) concludes that "their structure is not well-suited to accommodate the attested variation without becoming empirically vacuous", but emphasises that the paradox remains that the binding conditions "are too good to be false, and too bad to be true."

Over the same period, BT has also been deeply affected by shifting theoretical grounds, perhaps most notably the emergence of the Minimalist programme, whose elimination of stipulated and unprincipled theoretical devices rendered the binding conditions unformulable in the canonical form. ${ }^{3}$ BT was particularly likely to be a target for the reductionist programme, given the highly representational nature of the classical binding conditions and the emphasis on derivational (rather than representational) syntactic constraints within Minimalism (Epstein et al. 1998; Hornstein 2001; Reuland 2001). Furthermore, the very locus of the binding theory in the grammar disappears under a Minimalist approach since the programme dispenses with a modular organisation of UG. The fact that the framework provides no clear place for BT has thus led to its elimination from UG altogether, and indeed, later Minimalist theory (e.g. Chomsky 2005, 2007) has provided conceptual motivation for this: BT appears to comprise a kind of highly structured knowledge that Minimalism would

\footnotetext{
${ }^{3}$ The significant casualties from the perspective of BT include - but are by no means restricted to - D-Structure, S-Structure, government, and indices; see Freidin (1997), Hornstein (2001), Heinat (2008), Hicks (2009). An initial attempt by Chomsky (1993) to recast the binding conditions without such theoretical devices was largely unsuccessful (see e.g. the critique in Hicks 2009).
} 
not expect a simpler, less specified UG to harbour. The alternative Minimalist approach would be to assume that binding effects are derived from independent properties of the computational system ('narrow syntax'), and to this end a number of studies (e.g. Hornstein 2001, 2006; Kayne 2002; Zwart 2002; Reuland 2001, 2005; Hicks 2009; Gallego 2010) have provided possible reinterpretations of BT whereby relations between anaphors and their antecedents are established by the syntactic operations Merge, Move, and Agree.

Clearly, given the role that reflexive binding has played to date in helping to evaluate the status of UG in language acquisition, the demise of the traditional view of binding theory has crucial consequences for SLA theory and for our understanding of how non-native speakers come to acquire new knowledge in this grammatical area. Previous studies into the second language acquisition of reflexives, although following different theoretical variations of BT, have all assumed that reflexives are subject to some version of a universal (though possibly parameterised) Binding Condition A, with important implications for the nature of the learning task, and for the conclusions that can be drawn concerning parameter resetting and the role of UG in second language acquisition. ${ }^{4}$ With quite fundamental conceptual changes taking place in syntactic theory, it is timely to examine whether (and how) the L2 acquisition of anaphoric binding can be accommodated by recent Minimalist assumptions. This paper thus seeks to provide a new account of the L2 acquisition of reflexives following a Minimalist analysis of anaphoric binding which employs differences in the configuration of formal features between Korean and English anaphors to explain the language-specific properties without recourse to a highly structured and rich UG. ${ }^{5}$

Another advantage concerns the type of learning task that can be assumed with a featurebased account. The existence of variant, language-specific constraints necessarily highlights the relevance of experience in the acquisition of binding mechanisms. The process of acquiring new binding restrictions (either through parameter (re)setting, or feature acquisition/reconfiguration) must account for the acquisition of aspects of anaphoric binding which are specific to the target grammar. According to recent theoretical developments, UG should contain only a set of universal features and the operation Merge (Gallego 2011:541). Universal features provided by UG are selected and assembled onto functional categories to

\footnotetext{
${ }^{4}$ See, for example, Hamilton (1998) and White (2003) for a review.

${ }^{5}$ As noted above, any approach which assumes a simpler conceptualisation of Universal Grammar, consistent with what is known as 'approaching UG from below' (Chomsky 2007), is desirable under the Minimalist thesis.
} 
form the lexicon of a particular language (Chomsky 2007). Crosslinguistic differences that can be explained as differences in the configuration of formal features are, therefore, also desirable, a point which has recently been argued for in SLA theory (Lardiere 2009; Domínguez, Arche \& Myles 2011). In this study we show how independent, theoretically motivated analyses of reflexives in Korean and English make novel predictions for the L2 acquisition of these elements. Notably, we show that well-known (but long-problematic) interactions between locality and antecedent-orientation constraints, and their expected pattern of acquisition, can now be adequately explained by this new approach.

This article is structured as follows. Section 2 provides an overview of the role that locality and orientation constraints have played in explaining language-specific restrictions on binding. It will be argued that a Minimalist feature-based approach to binding is an appropriate solution that can explain well-known crosslinguistic behaviour in this domain. In section 3 we introduce the empirical study and examine the predictions of this new analysis, showing that it can also explain the acquisition of binding properties by adult L2 speakers. The proposed analysis makes clear predictions for patterns of acquisition at the level of the individual L2 speaker, rather than simply tendencies across groups of L2 speakers. The novel empirical contribution is thus the examination of individual learners' acquisition of orientation and locality, and we demonstrate that the results of the new empirical study bear out the predictions of the analysis; the group-level results are also consistent with established findings. The final section explains the main conclusions.

\section{The role of features in anaphoric binding}

\subsection{Locality and orientation constraints}

Differences in the restrictions of binding domains have been crucial to explaining variation in the distribution of anaphors across languages. While in many languages, such as English, reflexives require a 'local' antecedent to be present within some well-defined minimal syntactic constituent (e.g. the clause, the 'governing category' of earlier BT, or the 'phase' of later Minimalism), a number of languages, such as Icelandic, Chinese, Japanese and Korean, have anaphors that allow a non-local or 'long-distance' antecedent. ${ }^{6}$ Thus in the following

\footnotetext{
${ }^{6}$ See Koster \& Reuland (1991) for an overview.
} 
Korean example, the reflexive pronoun caki can be bound by a non-local antecedent Mary (or, equally, by the local antecedent Jane), whereas in English the reflexive can be bound only by the local antecedent:

2) a. Mary ${ }_{\mathrm{i}}$-nun $\mathrm{Jane}_{\mathrm{j}-\mathrm{i}} \quad \boldsymbol{c a k i}_{\mathrm{i} / \mathrm{j}}$-lul miwehanta-ko malhayessta (Korean) Mary-TOP Jane-NOM self-ACC hate-COMP said 'Mary said that Jane hates herself' or 'Mary said that Jane hates her'

b. Mary $\mathrm{i}_{\mathrm{i}}$ said that Jane ${ }_{\mathrm{j}}$ hates herself $*_{\mathrm{i} / \mathrm{j}}$

(English)

The interpretation of the reflexive in (2) is therefore ambiguous in Korean, but not in English. Selection of an appropriate antecedent for reflexives may also be determined by constraints on the 'orientation' of the reflexive towards its antecedent, that is, whether its antecedent is required to be a subject or not. The Korean reflexive caki appears to be subject-oriented (3a), whereas reflexives in English have no particular orientation restriction and so can be either subject- or non-subject-oriented (3b):

3) a. $\mathrm{John}_{\mathrm{i}}$-un Peter $\mathrm{j}_{\mathrm{j}}$-eykey $\boldsymbol{c a k i}_{\mathrm{i} / *_{\mathrm{j}}}$-eytayhayse malhayessta

(Korean) John-TOP Peter-DAT self- about told

'John told Peter about himself'

b. John told Peter $_{\mathrm{j}}$ about himself $\mathrm{i}_{\mathrm{i} / \mathrm{j}}$

(English)

The binding properties specific to Korean and English can then be characterised through the interaction of locality and orientation constraints, and this comparison bears out part of a more general pattern of interactions between locality and orientation observed crosslinguistically. Nonlocally bound reflexives (e.g. caki) generally exhibit a requirement for subject-orientation (Huang \& Tang 1991; Katada 1991) and reflexives that are unrestricted by orientation requirements (e.g. himself, etc.) must be locally bound. However, as summarised by Thomas (1995) and White (2003) among others, these implications only go one way. It is not the case that a reflexive which is subject-oriented will necessarily allow non-local binding; it may instead show a restriction to local binding only (as in the Korean reflexive caki-casin). Equally, it is not the case that a reflexive which is locally bound will always allow non-subject orientation; it may instead show a restriction to subject-orientation.

\footnotetext{
${ }^{7}$ The requirement for subject-orientation of caki does not appear to be entirely strict (Cho 1994; Gil 1998, 2000); this is clarified and accounted for in Section 2.2 below.
} 
As an empirical generalisation, then, the possibilities for combinations of locality constraints and orientation constraints are as represented in the following table, with the implications summarised in (4):

\begin{tabular}{|c|c|c|}
\hline Orientation & Local only & Local and non-local \\
\hline Subject only & $\begin{array}{c}\text { e.g. Korean } \\
\text { (caki-casin) }\end{array}$ & $\begin{array}{c}\text { e.g. Korean } \\
(\text { caki) }\end{array}$ \\
\hline Unrestricted & $\begin{array}{c}\text { e.g. English } \\
\text { (himself) }\end{array}$ & Not attested \\
\hline
\end{tabular}

Table 1. Locality and orientation constraints

4) Implications under the "classical" approach:

a. A reflexive freely allows subject and non-subject antecedents $\rightarrow$ Local binding only (English himself, etc.)

b. A reflexive freely allows local and non-local binding $\rightarrow$ Subject orientation only (Korean caki)

Any theory of binding thus needs to explain not only the behaviour of each type of anaphor, but also this general relationship between locality restrictions and orientation restrictions. As noted above, in order to account for this interaction, Manzini \& Wexler (1987) proposed modifications to the original BT, including a set of highly specified (and parameterised) locality restrictions. ${ }^{8}$ Alternative accounts have proposed that anaphors undergo covert movement at LF to achieve long-distance interpretations, from which it follows that only the closest subject to the anaphor following that movement is in a position to bind it in a local configuration (Lebeaux 1983; Pica 1991; Cole \& Sung 1994). Some proposals have also focused on differences regarding the lexical configuration of anaphors across languages (see the pioneering work by Reinhart \& Reuland 1991; 1993). Such analyses have paved the way for current Minimalist treatments, where orientation and locality restrictions are expected to

\footnotetext{
${ }^{8}$ See Thomas $(1995,1998)$ and Atkinson $(2001)$ for very precise criticism of Manzini \& Wexler's parameterised approach.
} 
follow from the specific featural properties of anaphors and their interaction with grammatical operations of the computational system.

In this paper, we pursue a Minimalist feature-based reinterpretation of the binding conditions which argues that local binding of reflexives can be interpreted largely as an operation of feature valuation employing the Agree operation, which copies values from the feature of one lexical item to another in a local configuration (as in the Chomsky 2000, 2001 framework). As noted in Section 1, the fundamental shift of this kind of analysis is that there is no 'Binding Condition A' per se, as the effects of the condition concerning locality and orientation are not stipulated as part of a binding theory, but simply derived by (i.e. reduced to) the independent constraints on feature checking operations between an antecedent and an anaphor (Heinat 2008; Hicks 2009). ${ }^{9}$ The reflexives in different languages will then involve different configurations of formal features. We begin by outlining our assumptions concerning the feature specifications of reflexives in English and Korean. It should be emphasised that the theoretical account we adopt below for each reflexive type has already been proposed in the theoretical literature, independently of any application to L2 acquisition.

\subsection{A feature-based account of locality and orientation constraints}

\subsubsection{English reflexives}

According to Hicks (2009), the relevant features involved in establishing binding syntactically are 'semanticosyntactic' features which are manipulated in the syntactic component of the grammar and are semantically interpretable, translating into logical variables at LF. This feature is thus termed [VAR(IABLE)], and the logical variable it introduces into the semantic representation of the sentence is identified by its feature value (e.g. $x, y, z$ ). Under this approach, the fact that English anaphors are referentially dependent elements is explained through the value of their [VAR] feature being absent when the anaphor enters the syntactic derivation. Like all other unvalued features, a reflexive's unvalued [VAR]

\footnotetext{
${ }^{9}$ The reduction of Condition A to the Agree operation naturally extends earlier attempts to reduce the binding conditions to core operations of the Minimalist framework. For example, Hornstein $(2001,2006)$ and Kayne (2002) aim to reduce binding to the Move operation, while Zwart (2002) aims to reduce binding to the Merge operation. A reviewer asks what the implications of the rejection of the canonical binding theory are for Binding Conditions B and C. As would be expected, these conditions have also been reduced to similar core syntactic properties in some of the works noted above (though the matter is orthogonal to the concerns of this article); see in particular Reuland (2001), Hornstein $(2001,2006)$ and Hicks (2009) for possible Minimalist reinterpretations of the other binding conditions.
} 
feature must be valued syntactically in order to ensure that the derivation converges: unvalued features violate the interface legibility condition of 'Full Interpretation'. The Agree operation copies the value of the antecedent's [VAR] feature onto the reflexive's (5a), and it is fairly transparent how this syntactic mechanism then maps onto the corresponding semantic representation $(5 b) .^{10}$

5) a. Every [OP: $\forall]$, [VAR: $x]$ boy loves himself $\left[\right.$ VAR: $\uparrow^{]}$

b. $\quad \forall x \cdot b o y(x) \rightarrow \operatorname{love}(x, x)$

Moreover, the advent of the phase-based implementation of the Minimalist framework (Chomsky 2000, 2001, 2004), which makes use of the phase as a generalised derivational domain, allows the locality component of binding to be straightforwardly accommodated, with the observation that phases coincide with local binding domains (Lee-Schoenfeld 2004; Canac-Marquis 2005; Heinat 2008; Quicoli 2008; Hicks 2009). In the phase-based model, feature valuation must take place before the completion of the minimal phase $(v \mathrm{P}$ or $\mathrm{CP})$ containing the unvalued feature (for our purposes, the reflexive). Thus, when Agree can apply locally (i.e. within a phase) between an antecedent and its anaphor in English, the interpretive dependency is successfully established; when it cannot, the derivation crashes, thereby deriving the impossibility of a non-local antecedent. For example in the derivation of (5a) above, represented in (6) below, the reflexive himself and its antecedent both merge within $v \mathrm{P}$. Thus, feature valuation can take place before the completion of the $v \mathrm{P}$ phase and the derivation converges. ${ }^{11}$

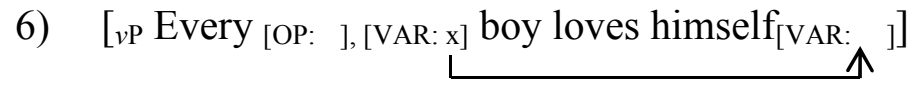

On the other hand, in the ungrammatical (7a) the minimal phase containing the anaphor completes before the antecedent enters the derivation, as in (7b). Either the feature remains unvalued causing the derivation to crash, or the feature is valued by an impossible antecedent bearing the wrong morphological feature set, causing a semantic mismatch between she and himself.

\footnotetext{
${ }^{10}$ The use of a quantifier NP (every boy) as an antecedent is used here for clarity of exposition, but extends to cases of anaphor binding by a referential NP where the binding by an operator is not as clear; see Hicks (2009: ch. 4) for full details.

${ }^{11}$ As expected, the subject moves into the canonical subject position after the feature valuation is has been established.
} 
7) a. *Every boy said that she loves himself

b. [Every [OP: $\forall],[$ VAR: $x]$ boy said that [vP she $_{[\mathrm{VAR}: \mathrm{y}]}$ loves himself ${ }_{[\mathrm{VAR}}$ ] ]]]

Since under this approach there is nothing to prevent either a subject argument or a nonsubject argument from valuing the reflexive's unvalued feature, there is no particular requirement concerning orientation of the pronoun to a particular antecedent, as is borne out by the empirical facts of English. The crucial consequence is that if Condition A of the classical BT can be reduced to the valuation of an unvalued feature, anaphoric binding conditions need not be part of UG, which in turn means that they need not be universal. It would be then expected that languages might use different grammatical resources to express apparently similar interpretations.

\subsubsection{Korean nonlocally bound reflexives ('caki')}

We next outline an analysis of reflexives in Korean within the theoretical framework assumed here, presenting analyses which we take to be among the more successful of those available within the framework adopted. ${ }^{12}$

The initial question is how to analyse the long distance Korean reflexives, which is the set that appear to be the most unlike the English reflexives. Early influential accounts of longdistance reflexivisation (Lebeaux 1983; Pica 1987; Cole, Hermon \& Sung 1990; Chomsky 1993; Cole \& Sung 1994) proposed successive-cyclic LF-movement of such anaphors into a position in which they could be locally bound (at LF, rather than S-structure). However, a number of issues have arisen with this account, and long-distance reflexives tend to exhibit a number of properties which suggest that they are substantively different from locally bound reflexives; these properties are not explained by LF-movement alone. Moreover, the property of long distance reflexivisation that is considered to be derived by this analysis, namely subject orientation, is also shown not to apply consistently to these reflexives.

\footnotetext{
${ }^{12}$ The reader should note that the picture concerning the range of Korean reflexives and their individual properties is complex, and somewhat obscured by the fact that the empirical facts beyond the basic data are contested and sometimes blur the distinction between 'preference' and 'grammaticality'. As emphasised by Gil (2000: ch. 3), long distance reflexives in Korean involve a complex mixture of syntactic, semantic, and pragmatic conditions, often resulting in variable degrees of acceptability that are difficult to capture through any one kind of approach. The reader is referred to the references noted in this section for further empirical issues related to the relevant theoretical approaches.
} 
Korean long-distance reflexives, caki and casin, exhibit a number of properties that are not shared with 'prototypical' reflexive pronouns, as summarised by Sohng (2004) and Han \& Storoshenko (2009). These authors show that caki can take an antecedent which does not ccommand the reflexive, plural forms of the reflexive may take 'split' antecedents, and that the long-distance reflexive may in fact be unbound in its sentence, in which case it takes arbitrary (first or second person) reference. These properties are generally considered to be characteristic of pronouns, and not bound anaphors. Furthermore, as stressed by Cho (1994), Gil (2000) and Sohng (2004), while canonical accounts of long distance reflexivisation derive a strict subject orientation of the reflexive due to the mechanism of long-distance reflexivisation, there are a relatively limited but significant range of cases where an object antecedent may bind caki/casin. ${ }^{13}$ In addition to the puzzling range of empirical facts, the main theoretical issue posed by Korean long-distance reflexives within the present framework is that if the mechanism for binding is driven by feature valuation (by the localityconstrained Agree operation), then clearly the system cannot apply in the same manner for nonlocal reflexives.

Broadly, we claim instead that nonlocal reflexives are not derived syntactically through feature valuation, but rather have their interpretation determined at LF by additional semantic properties of these reflexives. Indeed, independent theoretical work has arrived at a similar conclusion for caki. The empirical facts outlined have led several authors (e.g. Fukui 1984; Ueda 1984; Cole, Hermon \& Sung 1990) to argue that caki should be treated as an obligatorily bound pronominal, i.e. that caki is essentially a pronominal element, rather than an anaphoric one. Han \& Storoshenko (2009), pursuing ideas by Gil (1998), argue for a treatment of caki as essentially an obligatorily bound variable whose antecedent occupies an A'-position either via QR, or through topicalisation. This is consistent with Gil's (1998, 2000) analysis whereby caki is not restricted to binding by a subject but rather to binding by a topic. In this paper we will assume this much, in the spirit of these authors' conclusions. We may suppose then that the Korean long-distance reflexives are not bound via a syntactic operation but behave as bound variables, and hence at the level of semantic interpretation (LF) must be in the scope of an appropriate binder. Therefore, as Han \& Storoshenko (2009)

\footnotetext{
${ }^{13}$ Cho (1994) claims that the possibility for object orientation of long-distance anaphors in Korean (and Japanese) depends on the predicate used and its relation to subject/object viewpoint. For Gil (2000), the possibility of object orientation depends on a particular conception of the lexical argument hierarchy which she argues is available in the HPSG framework, with caki needing to be bound by a more prominent argument.
} 
show, their antecedent need not c-command it in overt syntax, provided that it can move covertly to a position where the reflexive is in its scope at LF. ${ }^{14}$ This also accounts naturally for the long-distance nature of reflexivisation, since quantifier binding at LF is not constrained by (syntactic) considerations of locality. With caki understood a variable bound by an appropriate topic, the question of what elements can bind it can be attributed to pragmatic factors affecting which elements can be interpreted as appropriate topics. Thus the semantic aspects of long-distance binding differ substantively from the kind exhibited by English reflexives; that is, reflexive binding in this case involves a different kind of mechanism of construal as there is no unvalued [VAR] feature that requires syntactic valuation. Either the feature value could be specified as its corresponding variable value at LF, e.g. [VAR: $x / y / z$ ] etc., or it could be considered to be a value that relates to its requirement to be topic-bound, e.g. [VAR: Topic]; for the purposes of the article nothing hinges on this technical matter.

\subsubsection{Korean locally bound reflexives ('caki-casin')}

Next we must deal with the locally bound reflexive, caki-casin. ${ }^{15}$ Tsoulas (2004) argues for a distinction in the treatment of caki and caki-casin, which is consistent with the fact that cakicasin, unlike caki, exhibits properties typical of locally bound reflexives. Equally, there is a distinction between caki and caki-casin concerning subject orientation: while some authors have claimed that nonsubjects are potentially antecedents for caki under the relevant syntactic/semantic/pragmatic conditions, to our knowledge there are no equivalent claims in the literature for the nonsubject binding of caki-casin. Tsoulas (2004) argues that unlike the long distance reflexive caki, the locally bound reflexive caki-casin derives reflexive interpretation by undergoing a process of cliticisation at LF to a c-commanding predicative head, such as $v \cdot{ }^{16}$ Tsoulas instantiates LF movement of caki-casin through the assignment of a specific value associated with a particular feature: the feature attribute is identified as 'Index' and the relevant feature value as 'Cliticisation ${ }_{\mathrm{LF}}$ ', i.e. [INDEX: Cliticisation $\mathrm{LF}_{\mathrm{LF}}$. However, it is

\footnotetext{
${ }^{14}$ Indeed, as borne out by the data, there need not always be an overt antecedent at all, since as Han \& Storoshenko (2009) demonstrate, Gil's (1998) account assumes that a null topic operator may occupy Spec, CP and hence bind caki.

${ }^{15}$ There is another class of Korean locally bound reflexives which have the morphological structure pronoun + casin. We leave these reflexives aside since their status appears to be somewhat less clear than caki-casin. See Lee (2001) for a discussion of the rarity of these reflexives in Korean and the fact that many native speakers find them unnatural.

${ }^{16}$ Note that this proposal is entirely distinct from earlier LF-movement approaches (e.g. Pica 1987) whereby certain reflexives head-move to INFL at LF, which was used as an explanation for the long-distance nature of the binding relation; here there is no cyclic INFL-to-INFL movement involved. Movement of anaphors into $v$ as an explanation for subject orientation is also proposed independently in recent work by Antonenko (2011).
} 
perhaps not particularly clear under this approach what triggers the reflexive to cliticise to a predicative head. A way of retaining Tsoulas's analysis but resolving this matter is to suppose that the reflexive caki-casin is considered to have the semantic function of 'reflexivising' a local predicate, where a reflexive predicate is understood as one which has two coreferential arguments (as in Reinhart \& Reuland 1993, for example). The interpretation of caki-casin is derived through its relationship with the predicate, schematised as follows:

$$
x \text { washę caki-casin } \rightarrow \lambda x \cdot \operatorname{wash}(x, x)
$$

If we consider Tsoulas's [INDEX] feature to be identified instead as the [VAR] feature proposed above, then we could assume that the feature bears the Cliticisation ${ }_{L F}$ value, i.e. [VAR: Cliticisation ${ }_{\mathrm{LF}}$ ] or perhaps better, that it specifies the fact that the reflexive is interpreted as a predicate reflexiviser, e.g. [VAR: Reflexive]. Regardless, reflexivisation of a predicate obligatorily results in the appearance of strict subject-orientation, although the nature of the interpretive relationship between the reflexive and its antecedent is mediated through the role of the reflexive as a predicate reflexiviser (unlike reflexives of the English type which establish the interpretive relationship directly with their antecedent through Agree). Just as Tsoulas notes for his analysis, this relationship between the reflexive and the predicate head means that only the subject of that predicate head is an available antecedent for that reflexive: for an object reflexive which reflexivises a $v$ predicate head, the only option for a reflexive interpretation is that the reflexive is interpreted as coreferential with the subject. ${ }^{17}$

\subsubsection{Summary of reflexive types in English and Korean}

In this approach, diversity in the behaviour of reflexives both within and across languages is explained through the diversity of mechanisms for establishing interpretive dependencies. Let us now summarise the mechanisms giving rise to the properties of the three types of reflexives relevant for the study. English local reflexives bear an unvalued feature [VAR], resulting in binding through the Agree mechanism. This derives the locality constraint and

\footnotetext{
${ }^{17}$ This analysis is very much in line with Hicks's (2009:224) suggestion that languages could in principle generate reflexive interpretations either by a reflexive serving to specify a predicate with the property of being semantically reflexive, as in this case, or by a reflexive directly receiving its interpretation from a syntactic antecedent (e.g. by Agree, as for the English reflexives).
} 
the absence of any particular orientation restriction. The Korean nonlocal reflexive (caki) involves a valued feature [VAR: Topic], resulting in a semantic variable-binding mechanism at LF, and deriving the fact that the reflexive exhibits some of the properties of pronouns rather than anaphors, including the absence of locality constraints. The Korean local reflexive (caki-casin) involves a valued feature [VAR: Reflexive] resulting in a semantic binding mechanism where the reflexive reflexivises its local predicate head, explaining subject orientation and the properties of anaphor binding (strict c-command, etc.) by contrast with caki.

We summarise our analysis for the reflexives attested in Korean and English in the following table and provide a new set of implications in (9):

\begin{tabular}{|c|c|c|c|}
\hline & \multicolumn{2}{|c|}{ Korean } & English \\
\hline Reflexive & $\begin{array}{c}\text { caki or casin } \\
\text { ('self') }\end{array}$ & $\begin{array}{c}\text { caki-casin } \\
\text { ('self-self') }\end{array}$ & $\begin{array}{c}\text { himself } \\
\text { (etc.) }\end{array}$ \\
\hline $\begin{array}{c}\text { Syntactic } \\
\text { Feature }\end{array}$ & $\begin{array}{c}\text { Valued feature } \\
\text { [VAR: Topic] }\end{array}$ & $\begin{array}{c}\text { Valued feature } \\
\text { [VAR: Reflexive] }\end{array}$ & $\begin{array}{c}\text { Unvalued feature } \\
\text { [VAR: _ }\end{array}$ \\
\hline Mechanism & $\begin{array}{c}\text { Semantic (Variable } \\
\text { binding by Topic) }\end{array}$ & $\begin{array}{c}\text { Syntactic } \\
\text { (Reflexivisation } \\
\text { via Cliticisation }\end{array}$ LF $)$ & $\begin{array}{c}\text { Syntactic (Referential } \\
\text { dependency via } \\
\text { Agree) }\end{array}$ \\
\hline Orientation & Topic-only & Subject-only & No restriction \\
\hline $\begin{array}{c}\text { Locality } \\
\text { restriction }\end{array}$ & $\begin{array}{c}\text { Local or long-distance } \\
\text { antecedent }\end{array}$ & $\begin{array}{c}\text { Local predicate } \\
\text { only }\end{array}$ & $\begin{array}{c}\text { Local antecedent } \\
\text { only }\end{array}$ \\
\hline
\end{tabular}

Table 2. Syntactic and semantic properties of Korean and English reflexives

9) Implications under the feature-based approach:

- Unvalued feature [VAR:__ ] $\rightarrow$ Agree mechanism = local-only binding

- Valued feature [VAR: Reflexive] $\rightarrow$ Syntactic predicate reflexivisation mechanism (e.g. Cliticisation ${ }_{\mathrm{LF}}$ to $v$ predicate head $)=$ subject-only orientation, local only reflexivisation

- Valued feature [VAR: Topic] $\rightarrow$ Semantic bound variable interpretation restricted to topic binding (Gil 2000) = topic-orientation (close correlation with subjectorientation, but not strictly), with binding potentially at long-distance 
A significant consequence of this analysis is that two distinct mechanisms for binding give rise to a binding configuration restricted to only local binding. In one instance (e.g. English reflexives), a locality constraint arises due to the locality constraints on Agree; in the other (e.g. Korean caki-casin), a locality constraint arises due to the relevant feature cliticising only to a local predicate. Another consequence is that the approach relates subject orientation not directly to the locality of the reflexive, but to the reflexivisation mechanism. Finally, subject orientation is not as straightforward a matter as is commonly assumed. Strict syntactic subject orientation is derived through the relevant reflexivisation feature of caki-casin and consequently cliticisation at LF to a predicate head. 'Weak' subject orientation of caki (in the terms of Cho 1994) is derived by a requirement for binding by a topic (which is typically but not uniquely - a subject). The alternative mechanism derives the possibility of nonsubject orientation from the use of the syntactic dependency mechanism (Agree), where a concept such as orientation has no role.

It should be clear that a Minimalist approach must aim to treat locality and orientation as epiphenomena, the 'superficial' consequence of some independent and more general syntactic constraint or operation (e.g. the result of cliticisation to a predicative head in the case of local Korean reflexives, the locality constraints on the operations of Agree and Move, due to the phase-based derivation, etc.). This general approach explains the aforementioned interactions between locality and orientation, while at the same time essentially unpacking these two concepts - often taken to be primitive within canonical theories of binding - from the binding theory. We thus formally dissociate locality and orientation and derive their properties through independent mechanisms relating to the feature specifications of different kinds of reflexives: the theory of binding does not specify the concepts of orientation and locality, and indeed the grammar harbours no theory of binding per se.

The significance of this approach to our understanding of acquisition patterns lies in the fact that these epiphenomena can now have more than one possible origin, and hence can behave in slightly different ways. For example, both caki and caki-casin have been claimed to be subject-oriented, but as shown in this section there are significant differences. This is due to the appearance of subject orientation arising for separate reasons in each case: Topic-binding for caki, cliticisation at LF for caki-casin. Similarly, and which has been the focus of our attention, locality conditions arise for separate reasons in caki-casin and in English reflexives: the locality requirement of cliticisation to the most local predicate head at LF for caki-casin, the requirement to value a feature before the end of the phase for English 
reflexives. This kind of flexibility - while at the same time retaining the main empirical generalisations - is in principle impossible in canonical binding theories, where locality is just locality, and orientation is just orientation.

\subsection{Accounting for the interaction between locality and orientation in L2 acquisition}

One of the main findings arising from previous research into the L2 acquisition of binding is that knowledge of locality seems to be consistently in place before orientation is acquired ${ }^{18}$ In particular, Finer (1991) examines the acquisition of locality and orientation constraints of English reflexives by Korean, Japanese and Hindi learners using a picture identification task. The majority of learners in this study correctly accept the 'local binding only' option, but show a robust preference for the 'subject binding only' option. Extending work by Finer \& Broselow (1986), Finer argues that UG constrains learners' knowledge of anaphoric binding but that they also choose an intermediate value of locality which is neither the one represented in the L1, nor in the L2. Hirakawa (1990) uses a multiple-choice comprehension task to test knowledge of locality and orientation constraints by Japanese speakers of English. The results of this study also show the same pattern of dissociation of locality and orientation, although Hirakawa rejects the possibility that L2 speakers may be representing an intermediate value of the locality parameter since a large number of the learners in this study appear to have set the value to the least restricted option. In a later study, Eckman (1994) uses a picture identification task to investigate the acquisition of reflexives by learners of English and Japanese by speakers of Arabic, Japanese, Mandarin and Spanish. Although Eckman finds no asymmetry between finite and non-finite clauses (contra Finer 1991) this study also shows that learners systematically bind the English reflexive to a local subject antecedent.

In light of these results, a central question guiding L2 research on this area has been how existing approaches to binding (i.e. how locality and orientation are derived) can account for persistent problems with orientation in acquisition (see Thomas 1991). Thomas (1995) specifically argues for a focus on examining the predictions that arise from the (theoreticallymotivated) interaction between locality and orientation constraints under the LF movement approach (Pica 1987; Battistella 1989; Cole, Hermon \& Sung 1990; Katada 1991). Thomas's

\footnotetext{
${ }^{18}$ This is consistent with the general presupposition, regardless of the theoretical approach adopted, that long-distance binding should not be acquired if acquisition of local binding is not attained first (see White 2003 for detailed discussion).
} 
analysis builds on Pica's (1987) observation that long-distance binding implies subject orientation but that subject orientation does not imply long-distance binding, an important point which was not appropriately clarified in Manzini \& Wexler's (1987) parameterised account. The overall question that Thomas sets out to answer in this study is whether L2 Japanese speakers who demonstrate knowledge of long-distance binding also know that only subject orientation is allowed in Japanese, and whether L2 speakers who know the restrictions regarding non-subject antecedents also know that they must be locally bound. Although in Thomas's analysis, crosslinguistic differences are analysed as arising from "the differing movement privileges of different kinds of reflexives: long-distance reflexives like Japanese zibun or Chinese ziji can move in LF positions from which only a subject NP ccommands them (Thomas 1995: 213)", the BT conditions are not specifically rejected in her analysis.

Thomas examined data from 58 L2 speakers of Japanese (34 in a low proficiency group and 24 in a high proficiency group) from a variety of L1 backgrounds collected via a truth-value judgment task. The interesting finding is that although roughly half of the L2 speakers (23 out of 54 speakers) correctly allow zibun to be bound at long distance, only 16 out of those 23 speakers correctly assign a subject antecedent to zibun (i.e. they correctly reject a non-subject antecedent). This means that 7 non-native speakers (and 3 native speakers) allow LD zibun to be associated with an object, exactly the type of behaviour which should not be allowed by UG under the LF-movement approach. Furthermore, the expected locality-orientation relationship which is crucially presupposed under the LF approach has not been attested either in studies which have looked at clustering effects of properties of reflexive binding such as binding domain, orientation and c-command (See Christie \& Lantolf 1998 and Yip \& Tang 1998). ${ }^{19}$ Despite the advantages of the LF-movement approach over previous accounts, whether this approach can fully explain the specific route of L2 acquisition of locality and orientation constraints remains essentially unclear. ${ }^{20}$

It is important to note that in previous studies the mechanism responsible for anaphoric binding was considered to be the same for all languages (i.e. arising from Condition A). This presupposition, however, does not hold for the feature-based account proposed in the current

\footnotetext{
${ }^{19}$ White (2003) notes how a potential problem for Christie \& Lantolf's clustering approach is that they assume that a twoway relationship between locality and orientation exists, when this is clearly not the case.

${ }^{20}$ See Sections 2.2.2 and 2.2.3 for a review of some theoretical issues of the LF-movement approach to binding.
} 
study, where the languages may instantiate different specifications of lexical features to specify referential dependencies. A crucial consequence of the feature-based approach, then, is that even if L2 speakers show target knowledge of locality restrictions, as shown in previous research, this cannot be taken as evidence that L2 speakers have acquired the correct mechanism for anaphoric binding in the target grammar. As noted in section 2.2, adopting the outline of Tsoulas's (2004) analysis of caki-casin explains why this reflexive is both locally bound and subject-oriented; adopting Hicks's (2009) analysis of English reflexives explains why these reflexives are both locally bound and unrestricted by orientation. Knowledge of locality conditions in the L2 necessarily entails having acquired a different mechanism for anaphoric binding, under this new approach. It is therefore possible that in the case of Korean speakers of English, transfer of the [VAR: Reflexive] feature (which is responsible for the locality of caki-casin in Korean) into English can explain why these speakers show what appears to be targetlike behaviour regarding locality constraints, but not orientation. In this case, Korean speakers may treat the corresponding anaphoric feature as being valued (i.e. the Korean option).

We are assuming an analysis by which orientation possibilities in English are not dependent on acquiring new restrictions on binding domains but on acquiring the appropriate featural configuration of the reflexive (the source of differences between the native and target languages). This analysis is consistent with the crucial role that formal features play more generally in linguistic theory and in language acquisition in Minimalism. Chomsky (2000, 2001) describes language acquisition as a process which involves at least the selection of features $\left[F_{L}\right]$ from a universal inventory made available by $U G$ and the use of those feature to construct lexical items $\left(\operatorname{Lex}_{\mathrm{L}}\right)$ in a process known as 'feature assembly'. Speakers of a second language already possess an array of lexical items in their native language as the result of the assembly process described above. Assuming that L1 grammars constitute the initial state of the L2 (see Schwartz \& Sprouse's (1996) 'Full Transfer/Full Access' model), learners would initially assume the feature configuration of their native grammars in the L2 that they are acquiring. Consistent with this analysis, recent research has argued for an examination of the role that feature (re-)assembly plays in the acquisition of a second language (Lardiere 2008, 2009). Under Lardiere's 'Feature Assembly' analysis, learners would need to reconfigure the feature values of the L2 in appropriate functional categories and lexical items. This reconfiguration of features is possible via access to UG and on the basis of appropriate positive evidence. 
We thus propose that the learning task for L1 Korean learners of English is to replace a valued [VAR] feature with an unvalued version of the feature, resulting in the necessity of Agree between the reflexive and an antecedent. It is not until Korean speakers change the value of the anaphoric feature to unvalued that binding will be appropriately achieved through the Agree operation; since Agree (and the specific conditions for its application), is universally available through UG, knowledge of locality and orientation constraints will naturally ensue and will not have to be learnt. The validity of this analysis for the L2 acquisition of English binding restrictions is examined in the empirical study introduced in the next section.

\section{The study}

The study was designed to examine the role of features in the acquisition of locality and orientation constraints of English reflexives by a group of Korean speakers.

\subsection{Participants}

The experimental group comprised 70 Korean learners of English who were living in Korea at the time of testing. The participants were divided into three proficiency groups (19 lowintermediate, 26 intermediate and 25 advanced learners) according to the scores obtained in an English proficiency test adapted from the Macmillan Placement Test (2007) available online. The control group consisted of 20 undergraduate native speakers of English of similar ages. A one-way ANOVA indicated a highly significant difference across the three nonnative groups with respect to their English proficiency $(F(2,67)=157.397, p=0.000)$. The participants' background information is summarised below: 


\begin{tabular}{|c|c|c|c|c|}
\hline Group & $\begin{array}{c}\text { Mean } \\
\text { age }\end{array}$ & $\begin{array}{l}\text { Mean age of } \\
\text { first exposure } \\
\text { to English } \\
\text { (years) }\end{array}$ & $\begin{array}{l}\text { Mean time } \\
\text { learning } \\
\text { English } \\
\text { (years) }\end{array}$ & $\begin{array}{c}\text { Mean scores in } \\
\text { proficiency } \\
\text { test }(\mathrm{n}=50)\end{array}$ \\
\hline $\begin{array}{c}\text { Low- } \\
\text { intermediate } \\
(\mathrm{n}=19)\end{array}$ & $\begin{array}{l}19.6 \\
(1.4)\end{array}$ & $\begin{array}{c}9 \\
(2.7)\end{array}$ & $\begin{array}{l}10.6 \\
(1.9)\end{array}$ & $\begin{array}{l}29.4 \\
(3.2)\end{array}$ \\
\hline $\begin{array}{l}\text { Intermediate } \\
\qquad(\mathrm{n}=26)\end{array}$ & $\begin{array}{l}21.9 \\
(2.2)\end{array}$ & $\begin{array}{c}9 \\
(2.3)\end{array}$ & $\begin{array}{l}12.3 \\
(2.7)\end{array}$ & $\begin{array}{l}36.7 \\
(1.6)\end{array}$ \\
\hline $\begin{array}{l}\text { Advanced } \\
(\mathrm{n}=25)\end{array}$ & $\begin{array}{l}20.4 \\
(2.0)\end{array}$ & $\begin{array}{c}8.9 \\
(1.8)\end{array}$ & $\begin{array}{l}11.8 \\
(2.6)\end{array}$ & $\begin{array}{l}41.6 \\
(1.9)\end{array}$ \\
\hline $\begin{array}{c}\text { Total } \\
(\mathrm{n}=70)\end{array}$ & $\begin{array}{l}20.7 \\
(2.2)\end{array}$ & $\begin{array}{c}8.9 \\
(2.2)\end{array}$ & $\begin{array}{l}11.6 \\
(2.5)\end{array}$ & $\begin{array}{l}36.5 \\
(5.3)\end{array}$ \\
\hline
\end{tabular}

Table 3. Summary of background information of L2 learners (means and standard deviations)

\subsection{Hypotheses}

Assuming that L1 Korean learners of English initially posit the Korean valued [VAR] feature into English (see Lardiere's $(2008,2009)$ 'Feature Assembly') the following two mutually exclusive hypotheses concerning the route of acquisition of English binding properties can be formulated:

1. Successful reanalysis of the [VAR] feature. This involves the successful rejection of the valued [VAR: Topic] and [VAR: Reflexive] features of Korean reflexives and the positing of an unvalued [VAR] feature on English reflexives. This scenario would be manifested by the acquisition of both locality and orientation constraints.

2. The $[\mathrm{VAR}]$ feature is not reanalysed. This means that Korean speakers incorrectly maintain a Korean feature value for English reflexives. There are two possible sources of transfer for these speakers: the valued [VAR: Reflexive] feature of cakicasin ('self-self'), and the valued [VAR: Topic] feature of caki ('self'). Crucially, if the feature of the Korean reflexive caki-casin which reflexivises only an immediately local predicate is transferred, Korean speakers could still treat L2 reflexives as being only locally bound in a manner which appears targetlike, 
despite the fact that the appropriate feature has not been reconfigured. Empirically, this scenario would be manifested by learners' apparent acquisition of locality, whilst problems with orientation would still be observed.

We are proposing that the acquisition of the absence of an orientation restriction in English necessarily involves positing an unvalued [VAR] feature on English reflexives. This, in turn, means that a scenario whereby orientation is acquired, but the locality restriction is not, is in fact not possible. Under our approach, this scenario cannot arise because - unlike the case of the acquisition of locality in hypothesis (2) - it is impossible to get orientation 'right' via L1 transfer without feature configuration having taken place. Hence an important corollary, which would refute hypotheses (1) and (2) - and force us to reject our assumptions concerning the features involved in binding - is that learners will not acquire orientation without having acquired locality as well. More significantly still, the unavailability of any feature configuration that could give rise to this empirical scenario makes a bold prediction at the level of the individual learner, captured by the third and final hypothesis:

3. No individual Korean speaker of English should demonstrate acquisition of orientation who does not demonstrate acquisition of locality.

Our study represents a departure from previous L2 studies in this area which have followed 'classical' analyses of binding whereby locality and orientation are determined by the same UG principle. The difficulty in explaining why orientation and locality should follow different patterns of acquisition faced by previous work disappears with our account, as we expect targetlike knowledge of both locality and orientation once acquisition has taken place. From a methodological perspective, an analysis of the patterns of acquisition of both locality and orientation by each individual learner is essential in order to test the hypotheses formulated in the current study.

\subsection{Methodology}

A picture verification task was developed and administered to a group of Korean speakers of English in order to evaluate the validity of our hypotheses. The task, adapted from Finer \& Broselow (1986), Chien \& Wexler (1990), Finer (1991) and White et al. (1997), was designed to test learners' knowledge of the relevant restrictions affecting reflexivisation in English. A story-based truth value judgment task similar to that used in White et al. (1997) 
was piloted with a few English native speakers and L2 Korean speakers, but the task was abandoned as the low-intermediate learners in particular found the task too demanding ${ }^{21}$. The picture verification task was eventually chosen because it eliminates the possibility that participants may be forced to consider a specific structure or interpretation that they may find unnatural (van der Weert 2002). ${ }^{22}$

The participants were presented with two pictures and a sentence containing a reflexive. They were asked to indicate the picture that best matched the input sentence by circling one of three options (A), (B) or (C). They were instructed to choose option (C) in cases where either picture (A) or (B) was possible. A sample of the test item is presented below:

\section{0) Sample test item:}

\section{Mr. Mask dreamed that Mr. Hat shot himself.}

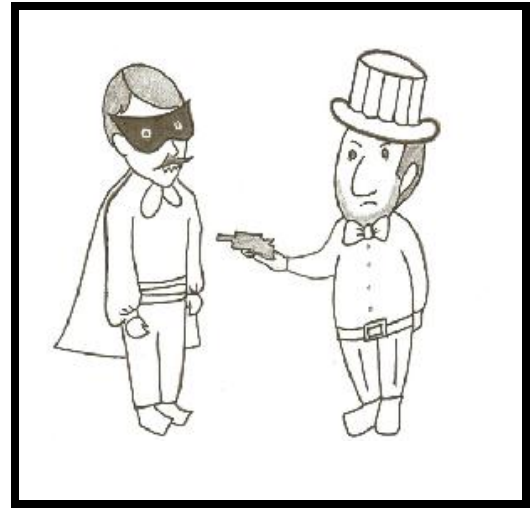

(A)

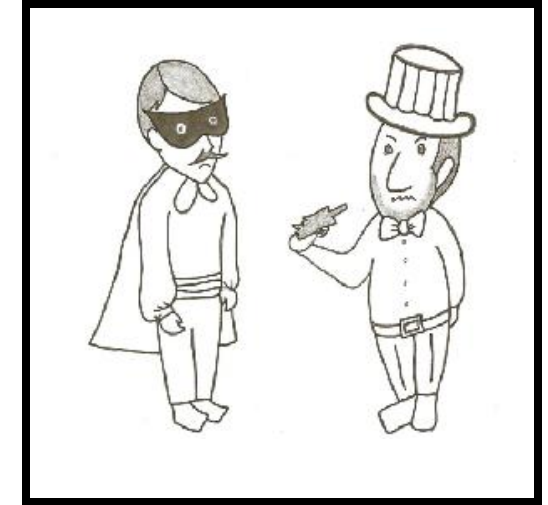

(B)

(C) either A or B

\footnotetext{
${ }^{21}$ A reviewer suggests that employing a truth-value judgment (TVJ) task would have been more appropriate than a pictureverification task, because a TVJ task can push respondents harder to declare what is impossible in their grammars. We accept the reviewer's point and acknowledge that although the results we present in this study show clear patterns of responses for locality and orientation, clearer patterns of responses for orientation results might have been obtained with a different task. We encourage future studies to consider including a TVJ in their methodological design to overcome this limitation.

${ }^{22}$ We are aware that a disadvantage of this particular task is it does not require participants to explicitly reject a picture as an appropriate representation of the test sentence (Schmitt \& Miller 2010; Ionin 2011). In L2 reflexive binding research, several methodological attempts have been made to improve the rate of responses confirming the 'expected' ambiguity and reducing preference bias (Lakshmanan \& Teranishi 1994; Wakabayashi 1996; White et al. 1997), with varying degrees of success. We took care to emphasise to the participants the requirement to read carefully all the options A, B and C in order to raise their sensitivity to potential ambiguity as far as possible.
} 
The task included 15 target sentences and five distractors. The target sentences were of three different types, and each type included five items. Table 4 shows the three types of sentence used in the task and the possible antecedents in each context. The distractors (Type 4) involved sentences with non-reflexive pronouns (him, her, etc.). Since pronouns cannot be bound by a local antecedent (the "Condition B effect"), the long-distance antecedent is typically selected in these contexts.

\begin{tabular}{|l|l|l|}
\hline \multirow{2}{*}{\multicolumn{1}{|c|}{ Sentence Types }} & \multicolumn{2}{c|}{ Possible antecedents } \\
\cline { 2 - 3 } & \multicolumn{1}{|c|}{ Korean } & \multicolumn{1}{c|}{ English } \\
\hline $\begin{array}{l}\text { Type 1 (n=5): Finite bi-clausal } \\
\text { sentences } \\
\text { e.g. Mr. Mask dreamed that Mr. Hat shot } \\
\text { himself. }\end{array}$ & $\begin{array}{l}\text { Mr. Hat (local) } \\
\text { or } \\
\text { Mr. Mask (LD) }\end{array}$ & $\begin{array}{l}\text { Mr. Hat } \\
\text { (local only) }\end{array}$ \\
\hline $\begin{array}{l}\text { Type 2 ( } \mathrm{n}=5) \text { : Non-finite bi-clausal } \\
\text { sentences } \\
\text { e.g. Miss Curly asked Miss Princess to } \\
\text { spray herself } \text { with perfume. }\end{array}$ & $\begin{array}{l}\text { Miss Princess (local) } \\
\text { or }\end{array}$ & $\begin{array}{l}\text { Miss Curly (LD) } \\
\text { (local only) }\end{array}$ \\
\hline $\begin{array}{l}\text { Type 3 (n=5): Mono-clausal sentences } \\
\text { e.g. Mr. Hat showed Mr. Mask a } \\
\text { reflection of himself in the mirror. }{ }^{23}\end{array}$ & $\begin{array}{l}\text { Mr. Mask } \\
\text { (subject only) }\end{array}$ & $\begin{array}{l}\text { Mr. Hat (subject) } \\
\text { or } \\
\text { Mr. Mask (object) }\end{array}$ \\
\hline \begin{tabular}{l} 
Type 4 (n=5): Distractors \\
\multicolumn{2}{|c|}{ Not relevant to the study }
\end{tabular} \\
\hline
\end{tabular}

Table 4. Sentence types and possible antecedents

Type 1 and 2 sentences were designed to test the locality constraint in finite and non-finite biclausal sentences respectively. The decision to distinguish between these two types of input

\footnotetext{
${ }^{23}$ A reviewer notes that the example sentence constitutes a controversial construction (a 'picture NP' without a possessor) that has proved difficult to analyse in syntactic theory in that it is not certain that they obey the usual constraint on locally bound reflexives. Some authors (notably Pollard \& Sag 1992; Reinhart \& Reuland 1993) have claimed these are not true reflexives but 'logophoric' reflexives, exempt from Condition A of the binding theory. A fairly neutral position is that of Hicks (2009), who argues that this configuration satisfies the locality requirement for a locally bound reflexive, but also allows, for independent reasons, the presence of a logophoric reflexive; essentially, a reflexive in this position is ambiguous, then, between the two lexical items. Three of the five test sentences for Type 3 involved picture-NPs of this kind, and no pattern in the responses across these three sentences was observed which would indicate that either the native controls or the learners handled these reflexives differently from the 'unambiguously' local reflexives.
} 
sentence is based on findings from previous research, which has revealed an asymmetry in the pattern of responses consistent with this (finite/non-finite) distinction. ${ }^{24}$

For the sample test item above, choosing either Mr. Hat or Mr. Mask as an antecedent (option C) or the LD antecedent Mr. Mask only (option A) would show that learners apply their L1 reflexivisation mechanism to the English reflexive. Choosing Mr. Hat only (option B) as an antecedent would be consistent with a targetlike analysis of reflexivisation, restricted to a local antecedent. However, as noted in Section 2.3, confirmation that learners' targetlike performance in locality contexts reveals successful acquisition of the new syntactic feature can only be achieved by analysing the results for orientation (Type 3 ) as well. This is because we are assuming that the appropriate choice of only a local antecedent can be explained by two different mechanisms: successful acquisition of the feature specification of English reflexives (in which case acquisition of orientation constraints is expected as well), or transfer of the feature value equivalent to that of the local Korean reflexive caki-casin (in which case the acquisition of the absence of an orientation constraint is not expected).

\begin{tabular}{|l|c|c|c|}
\hline & Domain targeted & Clausal type & Expected answer \\
\hline Type 1 & Locality & Finite bi-clausal & Local only \\
\hline Type 2 & Locality & Non-finite bi-clausal & Local only \\
\hline Type 3 & Orientation & Mono-clausal & Either subject or non-subject \\
\hline
\end{tabular}

Table 5. Sentence type details

All of the test items were presented randomly. Instructions were given orally and in written form in the participants' native language. There was no time limit to finish the task and participants were instructed not to change their original answers.

\footnotetext{
${ }^{24}$ The feature-based approach to binding does not specifically predict a contrast between binding across a finite and a nonfinite clause boundary, although a number of explanations for this are possible; see the discussion in Section 3.4.3.
} 


\subsection{Results}

This section provides a descriptive and statistical analysis of the group data. A paired-sample $t$-test was used for the within-group comparison and a one-way ANOVA with post-hoc Tukey HSD was used for the across-group comparison. Table 1 in the Appendix shows percentages of all responses obtained from the three Korean L2 groups and the English control group for all sentence types.

\subsubsection{Group results (locality)}

The following graph displays percentages of correct responses for Type 1 and Type 2 sentences (those targeting locality constraints). These results show general preferences for local antecedents across both Type 1 and Type 2, although for all groups of learners this preference is stronger in Type 1 than in Type $2 .{ }^{25}$

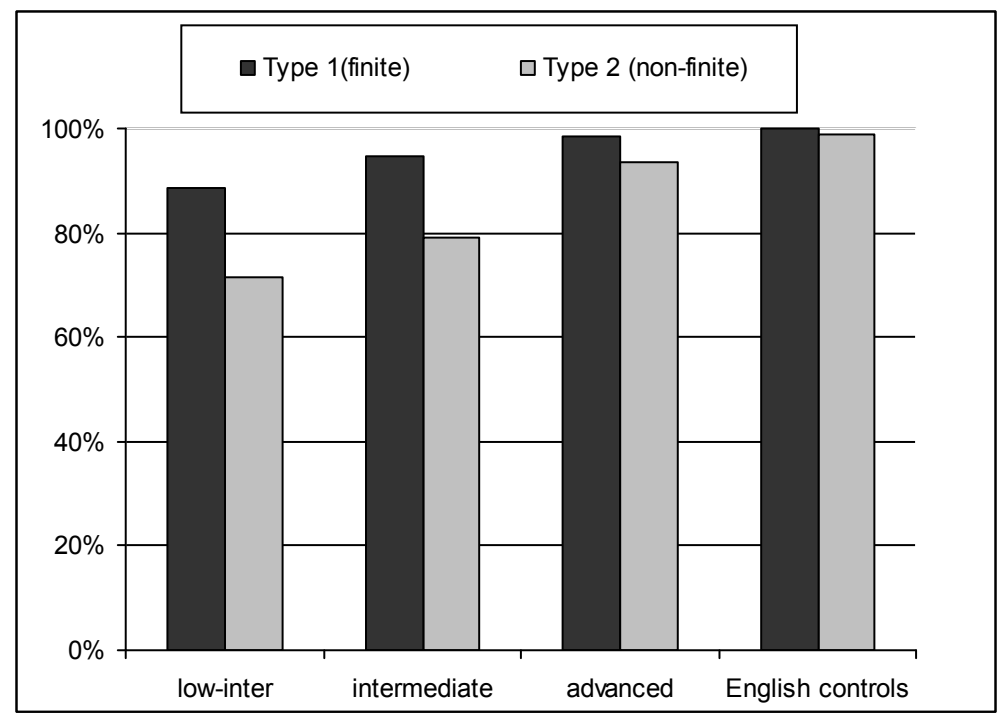

Figure 1. Across-group comparison of locality results

For the Type 1 sentences, a significant main effect was found for the across-group comparison $(F(3,86)=6.976, p<0.05)$. The low-intermediate group was found to be significantly different to all other groups ( $p<0.05$ in all cases). In contrast, no significant

\footnotetext{
${ }^{25}$ For convenience, here, and elsewhere, we use the term 'preference' in the somewhat loose sense, determined by the number of times that a group selects a particular option rather than an alternative or alternatives. Strictly speaking, we have not probed the 'preferences' of individuals, as such, and we thank a reviewer for bringing this matter to our attention. We have retained the term in order to avoid cumbersome alternative descriptions and hope its use is not ambiguous to the reader.
} 
differences were found between the intermediate and the advanced groups $(p=0.6)$, the intermediate and the English control groups $(p=0.3)$, and between the advanced and the English control groups $(p=0.9)$. This implies that the performance of the low-intermediate group significantly differs from that of all the other groups. In contrast, all other groups behave similarly for this type of sentence. This result is consistent with similar findings from previous research which has shown a relatively high percentage of local binding in Type 1 sentences across different proficiency levels (e.g. Hirakawa 1990; Thomas 1991; Lakshmanan \& Teranishi 1994; Akiyama 2002; Jiang 2009).

The response pattern of Type 2 sentences is broadly similar to that of Type 1 in that there was also a clear preference for the local antecedent by all groups. A one-way ANOVA revealed a significant main effect for the between-group comparison $(F(3,86)=14.397, p<0.05)$ in the choice of local binding. A post-hoc Tukey HSD revealed that there was a significant difference between the low-intermediate and all the other groups ( $p<0.05$ for all comparisons) and between the intermediate and all other groups $(p<0.05)$. However no significant effect was found between the advanced group and the English controls $(p=0.7)$. These results indicate that the acceptance of the local antecedent only in the low-intermediate and intermediate groups is significantly different to the advanced and the English control groups. In contrast, the advanced group and the English control group behave similarly regarding their selection of the local antecedent in Type 2 structures. That is, only the advanced L2 group can be said to perform in a nativelike way for this sentence type.

A paired-sample $t$-test was used for the within-group comparison. All L2 groups showed a significant effect between Type 1 and Type 2 sentences $(p<0.05)$; in contrast, the same difference was not significant in the case of the control group $(p=0.3)$. This result shows that only the English group treats Type 1 and Type 2 sentences in a similar fashion and that L2 learners seem to have more difficulty with reflexive binding (in the sense that they produce lower levels of nativelike performance) when the sentence includes a non-finite clause.

Next we examine the consistency of the participants in selecting only the appropriate local antecedent in Type 1 and Type 2 sentences, as shown in Table 6. The table shows the number 
and percentage of participants within each group who selected only the appropriate local antecedent for four out of the five tokens instantiating each sentence type: ${ }^{26}$

\begin{tabular}{|l|c|c|c|c|}
\hline & \multicolumn{2}{|c|}{$\begin{array}{c}\text { Type 1 } \\
\text { (finite clauses) }\end{array}$} & \multicolumn{2}{c|}{$\begin{array}{c}\text { Type 2 } \\
\text { (non-finite clauses) }\end{array}$} \\
\hline $\begin{array}{l}\text { English controls } \\
\text { (n=20) }\end{array}$ & 20 & 100 & 20 & 100 \\
\hline $\begin{array}{l}\text { Advanced } \\
(\mathrm{n}=25)\end{array}$ & 25 & 100 & 25 & 100 \\
\hline $\begin{array}{l}\text { Intermediate } \\
(\mathrm{n}=26)\end{array}$ & 25 & 96 & 15 & 58 \\
\hline $\begin{array}{l}\text { Low-intermediate } \\
(\mathrm{n}=19)\end{array}$ & 15 & 79 & 10 & 53 \\
\hline
\end{tabular}

Table 6. Frequency (and percentages) with which a local antecedent was selected at least $80 \%$ of the time in Type 1 and Type 2 sentences.

We can see a progressive acquisition pattern in the responses for local binding in Type 1 and Type 2 sentences which corresponds to the learners' proficiency level, and a clear asymmetry in behaviour between finite and non-finite clauses for the lower proficiency learners. The data show that the English controls and advanced L2 speakers categorically reject a long-distance antecedent in both sentence types. In contrast, the two other L2 groups exhibit a different behaviour. In particular, the individual data demonstrate poor rates in the selection of the correct option for Type 2 sentences for the lower proficiency groups, which suggests that somewhat in contrast to the previous group results, a significant number of learners may not have a targetlike syntactic representation of locality at this stage.

\subsubsection{Group results (orientation)}

Type 3 structures were designed to test learners' knowledge of orientation restrictions in English. Although native controls might be expected to select the 'both' option given the absence of any orientation constraints in English, the controls chose the 'subject antecedent

\footnotetext{
${ }^{26}$ A few studies, such as Wakabayashi (1996), have considered the participants' responses to be consistently targetlike only if they correctly answer all sentences in the relevant type of structure. Many other studies (e.g. Thomas 1991, 1993) have instead regarded as consistently targetlike those participants who responded correctly two out of three times or three out of four times for each relevant structure.
} 
only' option $50 \%$ of the time. This result is in fact not completely unexpected, since similar behaviour has also been reported for English controls in previous studies (e.g. Thomas 1991; Yip \& Tang 1998); indeed, some studies (Hirakawa 1990; Eckman 1994; Wakabayashi 1996) have reported even lower preference rates for the 'expected' option for this group. ${ }^{27}$ The results for Type 3 structures show a clearly different pattern of responses for the control and the experimental groups. While $45 \%$ of the English controls allowed the expected 'both' interpretations in Type 3 sentences, only $5.2 \%$ of the low-intermediate, $7.6 \%$ of the intermediate, and $5.6 \%$ of the advanced groups accepted this option. There was no consistent improvement across groups with the L2 speakers' proficiency levels: $71.5 \%$ of the lowintermediate, $75.5 \%$ of the intermediate, and $75.2 \%$ of the advanced groups selected a subject antecedent only. Whereas all three L2 groups preferred the subject-only option significantly more often $(p<0.05)$ than the 'both' option, this difference was not significant for the control group $(p=1.00)$.

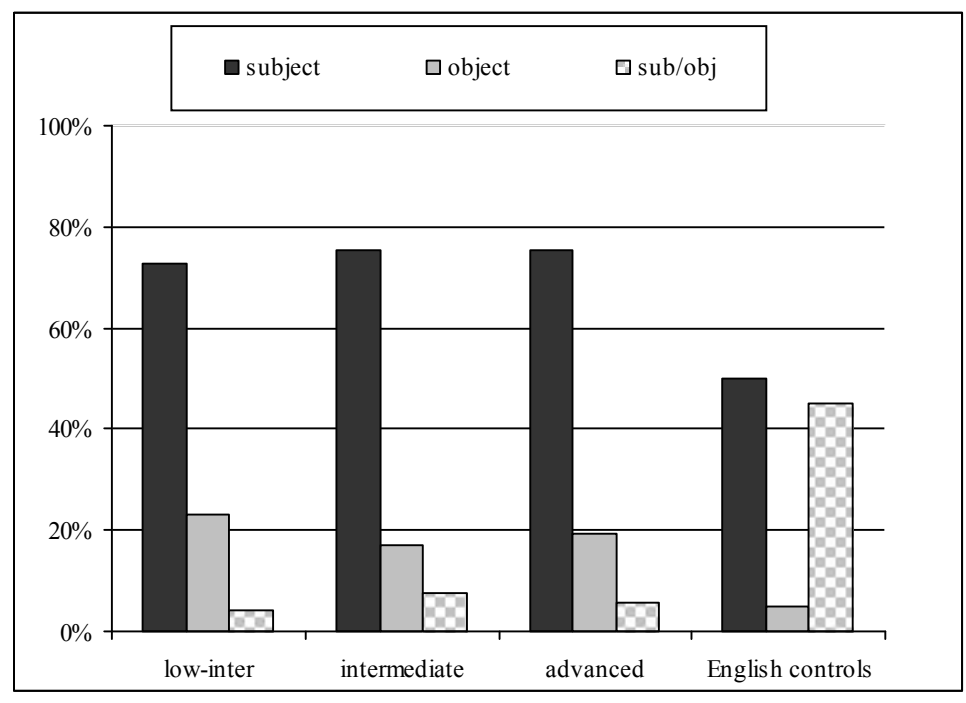

Figure 2. Across-group comparison of orientation results

It is worth noting that learners prefer the 'object antecedent only' option more often than the expected 'both' option (even 5\% of the native speakers chose this option). Although this option is not appropriate in either of the two languages, locally bound reflexives can take an

\footnotetext{
${ }^{27}$ See the discussion on attested preference for local subject antecedents in previous research in Section 2.3.
} 
object antecedent in some contexts in English but not in Korean. In our case, there is reason to believe that this result may be explained by the particular design of the task as learners tended to choose an object antecedent for the same few test items only. ${ }^{28}$ Incidentally, previous studies examining the effects of task design in the elicitation of binding responses (e.g. White et al. 1997) have also found that the specific type of truth-value judgement tasks used can affect the percentage of object antecedents elicited for both natives and L2 speakers.

A one-way ANOVA with scores of object/both binding as the dependent variable and scores of subject binding only as the independent variable revealed a significant effect across groups $(F(3,86)=4.950, p<0.05)$ for this sentence type. Further post-hoc Tukey HSD revealed that the acceptance of object/both bindings significantly differed between the English control group and the L2 groups $(p<0.05)$. However, no significant difference was observed between any of the L2 groups (low-intermediate and intermediate $(p=0.9)$, low-intermediate and advanced $(p=0.9)$, intermediate and advanced $(p=1.0))$. This result indicates that, in contrast to the behaviour of the controls, all learners significantly prefer a subject as the antecedent in Type 3 structures, regardless of their proficiency level.

To summarise, these results show what appears to be an asymmetry between the acquisition of locality and orientation constraints in English, closely mirroring those of previous research (e.g. Hirakawa 1990; Finer 1991; Eckman 1994; Thomas 1989, 1991, 1995; Wakabayashi 1996; Christie \& Landolf 1998; Yip \& Tang 1998; Yuan 1998). It is evident that acquiring the orientation possibilities for English reflexives remains a challenge to Korean speakers even at advanced levels of proficiency. On the other hand, results similar to those presented here have, naturally, led researchers to conclude that Korean speakers of English have acquired the locality restrictions of English. We argue, however, that the adopted analyses of the different reflexives in the two languages means that it may be possible for Korean speakers to show apparently nativelike behaviour regarding locality constraints by transferring knowledge from Korean anaphors into English. In this case, learners can show targetlike behaviour regarding locality restrictions by applying the L1 reflexive feature which is responsible for the local behaviour of certain Korean reflexives. An examination of the acquisition patterns of locality and orientation constraints by individual learners is necessary

\footnotetext{
${ }^{28}$ A great majority of the instances of 'object only' responses across all three of the L2 groups were attested for one of the test sentences in particular, namely "Mr Hat showed Mr Mask a reflection of himself in the mirror." The marked distinction between this sentence and the other four test sentences was not borne out in the native control data.
} 
in order to establish whether feature reanalysis has in fact taken place. While the group results confirm the results of previous studies, it is in the individual results where the most novel and significant findings of our study are revealed, as we now proceed to show.

\subsubsection{Individual results}

For the purposes of the analysis below, we assume that a learner has acquired locality if they prefer only a local antecedent in at least four out of five tokens (80\% acceptance rates) in Type 1 and Type 2 sentences. We assume that a learner has acquired orientation if they prefer a subject antecedent only (the Korean option) in less than $40 \%$ of the options ( 2 out of 5 tokens) in Type 3 sentences. It is important to note that we base our analysis of the orientation results on the 'subject only' option as we could not rely on the 'target' response of 'both subject/object binding' in this case as only a few learners (21\%) selected the expected option and never consistently (never over $40 \%$ of the time). Most of the learners opted for the 'subject only' or 'object only' options instead. ${ }^{29}$ Individual percentages of locality and orientation responses are available in Tables 2, 3 and 4 in the Appendix.

The individual participants' behaviour regarding their acquisition of locality and orientation was examined in six possible acquisition patterns:

\footnotetext{
${ }^{29}$ Although $70 \%$ of the native speakers chose the 'both' option at least once, only 7 of these controls (35\%) chose this option over $80 \%$ of the time. This result makes it difficult to draw a direct comparison between the learners' and controls' individual responses for orientation.
} 
Note: ' $\checkmark$ ' $=$ acquired/ ' $x$ ' $=$ not acquired

\begin{tabular}{|l|c|c|c|c|}
\hline $\begin{array}{l}\text { Acquisition } \\
\text { pattern }\end{array}$ & $\begin{array}{c}\text { Low-inter. } \\
(\mathrm{n}=19)\end{array}$ & $\begin{array}{c}\text { Intermediate } \\
(\mathrm{n}=26)\end{array}$ & $\begin{array}{c}\text { Advanced } \\
(\mathrm{n}=25)\end{array}$ & $\begin{array}{c}\text { Total } \\
(\mathrm{n}=70)\end{array}$ \\
\hline $\begin{array}{c}(1) \checkmark \text { locality } \\
\checkmark \text { orientation } \\
(10.5 \%)\end{array}$ & 2 & 3 & 7 \\
$(7.7 \%)$ & $(12 \%)$ & $(10 \%)$ \\
\hline $\begin{array}{c}(2) \checkmark \text { locality } \\
(\text { fin \& non-fin. }) \\
\times \text { orientation }\end{array}$ & $(31.6 \%)$ & $(50 \%)$ & $(88 \%)$ & $(58.6 \%)$ \\
\hline $\begin{array}{c}(3) \checkmark \text { locality } \\
(\text { fin. only) } \\
\times \text { orientation }\end{array}$ & $(36.9 \%)$ & $(38.5 \%)$ & $(0 \%)$ & $(24.3 \%)$ \\
\hline $\begin{array}{c}(4) \checkmark \text { locality } \\
(\text { non-fin. only }) \\
\times \text { orientation }\end{array}$ & 2 & 0 & 0 & 2 \\
\hline$(10.5 \%)$ & $(0 \%)$ & $(0 \%)$ & $(2.8 \%)$ \\
\hline $\begin{array}{c}(5) \times \text { locality } \\
\checkmark \text { orientation }\end{array}$ & $(0 \%)$ & $(0 \%)$ & $(0 \%)$ & $(0 \%)$ \\
\hline $\begin{array}{c}(6) \times \text { locality } \\
\times \text { orientation }\end{array}$ & $(10.5 \%)$ & $(3.8 \%)$ & $(0 \%)$ & $(4.3 \%)$ \\
\hline
\end{tabular}

Table 7. Frequency (and percentages) of appropriate locality and orientation responses in six different acquisition contexts

The hypothesis that we are considering is that the acquisition of English binding effects requires changing the specification of a feature which already exists in the learner's L1. If L2 speakers have successfully acquired the English-type feature configuration, they should demonstrate targetlike behaviour in both locality and orientation constraints (this would be consistent with our first hypothesis, Section 3.2). In our data this was the case for only 7 learners $(10 \%$ of all learners). The majority of learners $(85.7 \%)$, however, appear to possess targetlike knowledge of locality constraints whilst still showing persistent problems with orientation. This seems consistent with the data discussed in the group results.

In our examination of the acquisition of locality constraints we took into consideration the possibility that Korean speakers could be influenced by the interaction between locality and clausal syntactic properties (finite or non-finite) and that learners' choices may be influenced by properties which are specific to each of these two clause structures (reminiscent of Manzini \& Wexler's (1987) parameterised domain restrictions). We therefore distinguished 
between those learners who correctly show targetlike knowledge of locality constraints in both sentence types (scenario 2), in finite clauses only (scenario 3) and in non-finite clauses only (scenario 4). The results show that sentence type does not affect the advanced learners' responses as all of the learners who prefer the local binding option allow it in both finite and non-finite contexts. In contrast, although $50 \%$ of the intermediate learners correctly allow local antecedents in both contexts, $38.5 \%$ of speakers in this group also allow them in finite clauses only. Low intermediate learners also show a mixed behaviour as $31.6 \%$ allow local binding in both sentence types whereas $36.9 \%$ allow them in finite only contexts and $10.5 \%$ in non-finite contexts only. It appears that the type of clause (finite or not) is a factor which influences the behaviour of the intermediate and low intermediate groups. Indeed, as noted above, our study is not the first to find that learners have more difficulties in assigning appropriate antecedents if a sentence is non-finite, an observation which has been discussed in Finer \& Broselow (1986), Finer (1991), Matsumura (1994), Akiyama (2002) and Jiang (2009). For instance, Finer \& Broselow (1986) briefly explain how participants may have analysed the non-finite clauses as mono-clauses, so they may have treated the first NP as a subject and the second NP as an object. Finer (1991) argues that L2 speakers regard nonfinite sentences as double-object constructions, so that they allow an object NP as an antecedent. Matsumura (1994) also shows that learners have more difficulties choosing the correct antecedent for the verb want than for tell, suggesting that the clausal complement structure of specific English verbs is not appropriately perceived. Although the feature-based analysis of binding itself does not predict a contrast with respect to clause finiteness, it is clearly compatible with such explanations for the observed contrast. In our study, the observed clause-type effect disappears when L2 speakers achieve an advanced proficiency level which suggests that a lack of knowledge of other areas of the L2 grammar, such as specific properties of English clausal syntax, could explain these results. Interestingly, the observed difference between the advanced and intermediate learners was not captured by the group results presented in Figure 1 for the acquisition of locality restrictions.

The individual results are also able to reveal the role of experience as the number of learners who initially assume that long-distance binding applies to English reflexives decreases with proficiency (see results for scenario 2) and that the number of learners who correctly select local antecedents in all sentence types increases as well (see within group comparison between scenarios 2, 3 and 4). 


\subsection{Discussion}

As predicted by our first hypothesis, the results have shown that successful reanalysis of the [VAR] feature by learners - manifested by the acquisition of both locality and orientation constraints - is possible, although only a few of the learners tested showed evidence of this outcome. Although our results might seem to lend to support to the hypothesis that Korean L2 speakers of English acquire locality before orientation, we would argue that this is not the case. In contrast to previous research, we argue that the dissociation in the acquisition of these two types of constraints must, in fact, be taken as evidence that L2 speakers do not possess a nativelike representation of how binding is achieved in English, including relevant locality restrictions. Under the feature-based account proposed in this study, both locality and orientation properties in English are a by-product of the phase-based constraints on Agree, the binding mechanism available in this language, and are therefore expected to be simultaneously acquired. Since differences in the value of the relevant feature in Korean and English determine the type of binding mechanism available in each language, failure to reanalyse the English feature must necessarily be manifested by non-targetlike behaviour of both locality and orientation restrictions. This suggests, as predicted by our analysis, the impossibility of a scenario where Korean speakers would acquire locality but would not acquire orientation. This presupposition, however, seems to be contradicted by the fact that $85.7 \%$ of our learners appear to have acquired locality but not orientation (scenarios 2, 3 and 4). We argue, however, and in accordance with our second hypothesis, that in these 3 contexts, learners are able to show what appears to be targetlike behaviour of locality restrictions by transferring knowledge from their L1. Since the binding mechanism instantiated in Korean (dependent on a valued [VAR] feature) independently allows the appearance of local binding as well (through the choice of a feature value corresponding to that of the locally bound reflexive caki-casin), it may be the case that these speakers could 'correctly' prefer a local antecedent for English anaphors without changing the value of the feature, by transferring a mechanism from their own L1 grammar.

Our presupposition is thus that the data may suggest that learners can successfully achieve local binding via Agree, when they are still using the reflexivisation mechanism which allows local binding of certain anaphors in the L1. This would mean that $85.7 \%$ of learners, those who show the pattern of acquisition represented in scenarios 2, 3 and 4 (i.e. locality is acquired but orientation is not), have actually not successfully acquired the binding mechanism available in English. That is, they have not correctly reanalysed the 
reflexivisation feature that allows local binding to be achieved via Agree in English. In contrast, transfer of an L1 mechanism to approximate the L2 orientation behaviour is not available in this case which, in turn, means that Korean speakers of English cannot demonstrate what appears to be targetlike behaviour of orientation, unless they actually have reanalysed the appropriate feature. Thus, the $58.6 \%$ of learners who correctly chose a local antecedent without successfully acquiring the L2 orientation possibilities could not have arrived at such knowledge by using the appropriate L2 reflexivisation mechanism.

Finally, and perhaps most significantly, our results are fully consistent with hypothesis 3 inasmuch as one of the patterns of acquisition that should in principle be available is not attested by any learners in our data; namely the pattern represented in scenario 5 of Table 7 , where orientation is acquired but locality is not. If, as we are suggesting, the acquisition of the orientation restrictions (or rather, the lack thereof) in English necessarily involves reanalysing the relevant feature of the reflexive as an unvalued [VAR] in English, locality restrictions must be automatically acquired as well. This explains why not one of the learners examined show a pattern of acquisition which supports this acquisition route. As argued in Section 2.3, this finding provides crucial evidence that the feature-based approach makes the correct predictions for Korean learners of English since our approach, uniquely, predicts this particular scenario not to be possible.

In summary, our results show that we cannot conclude that locality is acquired before orientation using the results reported in this study. We argue that 'real' acquisition of locality restrictions in English is rare, whereas 'apparent' acquisition of locality is the most common behaviour in the case of these Korean speakers. One consequence of this analysis is that in contrast to the conclusions of previous research, we might consider locality - as well as orientation - to be an area of persistent difficulty for Korean speakers of English, since only a few learners in each group demonstrate that they have successfully reanalysed the reflexive feature to meet the L2 specifications. However, the results have also shown that although not through the right mechanism, most Korean speakers consistently (and appropriately) reject the possibility of long-distance binding in English, an option which is available in their L1. It is important to emphasise that what allows us to reach this conclusion is the rejection of the canonical binding theory and the adoption of theoretical mechanisms specific to each reflexive, as proposed in section 2.2. As argued, the general theory of binding adopted in this study is fully justified on independent theoretical grounds. A central aspect of the current 
approach is the decoupling of locality constraints from orientation constraints. Yet this alone is not a sufficient step, since as we have seen in Section 2.1, there are sufficient crosslinguistic tendencies to suggest apparent implications between locality and orientation for which explanation would be lost through simply detaching these two binding properties. The specific analysis of each class of reflexive each shows one way of accommodating this to our minds, the most successful of those available within current theoretical understandings - within a feature-based approach to binding.

\subsection{Further consequences}

An aspect which may seem difficult to explain is why long-distance binding is not allowed more often by these speakers, if L1 transfer seems to apply widely in this context. In this respect, we suggest that the fact that L1 transfer is only attested in the aspect of the L1 which overlaps with the L2 (local binding) seems to indicate that use of transfer is in fact rather selective and restricted only to the grammatical aspect where a similar option (despite underlying structural differences) appears to be possible in both languages. Furthermore, the morphological parallel between caki-casin and the English reflexives might also appear to be likely to give the learner a clear clue that English reflexives will bear properties closer to caki-casin rather than caki which, in turn, could prevent learners from applying long-distance binding widely in English. The correct rejection of the long-distance option also seems to indicate that, despite transfer effects, learners are not completely in the dark about the locality restrictions which apply in English (a conclusion which assumes a certain level of analysis of the target grammar by these speakers) but have found a way to behave that is largely consistent with the L2 by using knowledge from their own grammar. In this case, we can see how L2-induced restructuring is not necessary for these speakers to correctly associate a reflexive with a local antecedent in the L2. However, despite the fact that L1 transfer seems to have a positive effect for the representation of locality restrictions in this context, it also appears as if it may be preventing L2 speakers from acquiring the full range of structural configurations available in English. One such restriction concerns orientation, an area of the L2 which could not be inappropriately represented through transfer in this case.

The type of learning task we assume in this study, i.e. feature reanalysis, can also explain the selective nature of transfer in this context. Throughout this study we have hypothesised that in order for learners to achieve complete L2 competence in this domain they would need to 
assign an alternative value specification for the [VAR] feature to an existing feature in their L1: the feature value must be removed. In this respect, the appropriate feature in question does not need to be acquired (i.e. selected as part of the L2 grammar), but rather, reconfigured. This is the specific acquisition context which has been characterised as posing additional difficulty and an extra burden to learners (see Lardiere 2009:215). Indeed, it seems likely that the type of change in feature value (from or to a valued or unvalued feature in the L2) will also play an important part in determining how difficult the learning task is. Clearly, it would also be interesting to fully explore and compare the implications of the reverse situation, where the required shift is from a grammar where a particular feature is unvalued, to one where it is valued. This goal is, however, beyond the scope of the present study we must leave it for further research to examine this possibility and to provide a re-examination of the L2 binding data from languages which allow long-distance binding reported in previous studies.

We have also argued that in this particular case Full Transfer would allow learners to approximate nativelike behaviour without changing the binding mechanism used in the L2. An explanation for why acquiring this new feature value remains problematic for advanced learners could be the absence of the type of evidence which is crucial for the reanalysis of such a feature. In particular, it is possible to assume that the evidence that learners use to acquire binding restrictions in English is mostly provided by a structure where an anaphor is associated with a local subject antecedent (Mary loves herself/Mary says that Lola loves herself, etc.). The absence of evidence for long-distance binding in English would be quite robust. This type of input, however, cannot be used to confirm orientation properties of L2, as learners would also need to be exposed to structures where the local antecedent is an object (e.g. Paul told Lola about herself) in order to get evidence for the full range of English binding possibilities. Such input is crucial in reaching an understanding that predicate reflexivisation (involving cliticisation at LF) cannot be the mechanism used in English to derive this type of sentence and thus in supporting the necessary reanalysis of features, if we are assuming Full Transfer. It may be the case that lack of access to this key evidence plays a significant role in explaining why Korean speakers show a delay in acquiring English binding effects appropriately, despite access to UG being fully available; see White 1989, Schwartz \& Sprouse 1994, 1996, Lardiere 2009 for discussion on the role of positive evidence in L2 acquisition. 


\section{Conclusion}

This study has examined a new set of data on the L2 acquisition of binding-related phenomena and the interaction of orientation and locality constraints by adult L2 speakers of English. The aim of our study was to show that a re-examination of the acquisition of binding constraints within a feature-based approach provides an advantage over previous studies for two reasons. First, it allows us to reanalyse anaphoric binding, including crucial crosslinguistic differences, within the terms of current Minimalist theory and more broadly within recent conceptions of UG. In particular, we have shown that the acquisition of this grammatical area can still be accommodated by generative analysis, even if binding phenomena are no longer assumed to be determined by parameterised principles of UG (which is instead considered to be minimally specified under current Minimalist analysis). In our analysis, differences in locality and orientation restrictions observed cross-linguistically can still be fully accounted for, emerging from the value assigned to a feature in each language which is responsible for deriving reflexive interpretations.

Second, it allows us to make new concrete predictions about the pattern of acquisition of English reflexives, which instantiate the unvalued option for the relevant feature, by speakers of languages that select an alternative valued option for the feature (i.e. Korean). Our analysis has shown that the observed routes of acquisition regarding orientation and locality constraints are fully compatible with these predictions. Our analysis was also able to attest that changing the value of such a feature is difficult, requiring a type of evidence which learners may not readily have access to. This explains why only a few learners show target knowledge of both locality and orientation constraints, but also why most of the learners seem to extend the reflexivisation mechanism which is available in their L1 into English. Significantly, the fact that not one of the 70 learners in the study demonstrates successful acquisition of orientation without also demonstrating acquisition of locality bears out an important prediction of our approach.

A further relevant contribution of this study is that it can explain in a straightforward manner why there appear to be distinct routes of acquisition for locality and orientation constraints. Previous research, which assumed locality and orientation to be determined by the same UG principle, failed to appropriately account for the dissociation pattern observed in the L2 acquisition of these two properties. In our feature-based analysis, which formally dissociates orientation behaviour from locality and derives it instead from the particular binding 
mechanism, knowledge of orientation naturally ensues once L2 speakers have acquired the binding mechanism via Agree in English. As a consequence, the common pattern where speakers show apparent acquisition of locality constraints but not orientation is necessarily analysed as evidence that L2 speakers have not achieved a target grammar, even concerning locality. In our analysis, this behaviour must be interpreted as manifesting that the value of the existing feature has not been reconfigured according to L2 specifications. Only cases where L2 speakers show targetlike knowledge of both locality and orientation constraints demonstrate that L2 acquisition has taken place. Our approach to binding thus eliminates the possibility that locality and orientation constraints could pose 'apparently' different learning difficulties to the same L2 speakers.

\section{References}

Akiyama, Yasuhiro. 2002. Japanese adult learners' development of the locality condition on English reflexives. Studies in Second Language Acquisition 24 (1). $27-54$.

Antonenko, Andrei. 2011. On phases and tense dependency: Subjunctives and binding. Poster presented at the $29^{\text {th }}$ West Coast Conference on Formal Linguistics, April 22, University of Arizona.

Atkinson, Martin. 2001. Learnability and the acquisition of syntax. In Stefano Bertolo (ed.), Language acquisition and learnability, 15-80. Cambridge: Cambridge University Press.

Battistella, Edwin. 1989. Chinese reflexivization: A movement to INFL approach. Linguistics 27. 987-1012.

Bennett, Susan. 1994. Interpretation of English reflexives by adolescent speakers of SerboCroatian. Second Language Research 10 (2). 125-156.

Bennett, Susan \& Ljiljana Progovac. 1998. Morphological status of reflexives in second language acquisition. In Suzanne Flynn, Gita Martohardjono \& Wayne A. O’Neil (eds.), The generative study of second language acquisition, 187-214. Mahwah, NJ: Lawrence Erlbaum. 
Canac-Marquis, Réjean. 2005. Phases and binding of reflexives and pronouns in English. In Stefan Müller (ed.), Proceedings of the 12th International Conference on Head-Driven Phrase Structure Grammar, 482-502. Stanford, CA: CLSI Publications.

Chien, Yu-Chin \& Kenneth Wexler. 1990. Children's knowledge of locality conditions in binding as evidence for the modularity of syntax and pragmatics. Language Acquisition 1 (3). $225-295$.

Cho, Mi-Hui. 1994. On the orientation problem in Korean 'CAKI' binding and the typology of $\mathrm{X}^{0}$ reflexive binding. Kansas Working Papers in Linguistics 19 (1). 165-183.

Chomsky, Noam. 1981. Lectures on government and binding. Dordrecht: Foris.

Chomsky, Noam. 1986. Knowledge of language: Its nature, origins, and use. New York: Praeger.

Chomsky, Noam. 1993. A minimalist program for linguistic theory. In Kenneth Hale \& Samuel J. Keyser (eds.), The view from building 20: Essays in linguistics in honor of Sylvain Bromberger, 1-52. Cambridge, MA: MIT Press. Reprinted as chapter 3 of Chomsky 1995, 167-217.

Chomsky, Noam. 2000. Minimalist inquires: The framework. In Roger Martin, David Michaels \& Juan Uriagereka (eds.), Step by step: Essays on minimalist syntax in honor of Howard Lasnik, 89-155. Cambridge, MA: MIT Press.

Chomsky, Noam. 2001. Derivation by phase. In Michael Kenstowicz (ed.), Ken Hale: A life in language, 1-52. Cambridge, MA: MIT Press.

Chomsky, Noam. 2004. Beyond explanatory adequacy. In Adriana Belletti (ed.), Structures and beyond: The cartography of syntactic structures, 104-131. Oxford: Oxford University Press.

Chomsky, Noam. 2007. Approaching UG from below. In Uli Sauerland \& Hans-Martin Gärtner (eds.), Interfaces + recursion = language?: Chomsky's minimalism and the view from syntax-semantics, 1-29. Berlin: Mouton de Gruyter.

Christie, Katrien \& James P. Lantolf. 1998. Bind me up and bind me down: reflexives in L2. In Suzanne Flynn, Gita Martohardjono \& Wayne A. O’Neil (eds.), The generative study of second language acquisition, 239-260. Mahwah, NJ: Lawrence Erlbaum. 
Cole, Peter, Gabriella Hermon \& Li-May Sung. 1990. Principles and parameters of longdistance reflexives. Linguistic Inquiry 21 (1). 1-22.

Cole, Peter \& Li-May Sung. 1994. Head movement and long-distance reflexives. Linguistic Inquiry 25 (3). 355- 406.

Crain, Stephen \& Paul Pietroski. 2001. Nature, nurture and Universal Grammar. Linguistics and Philosophy 24. 139-185.

Domínguez, Laura, María J. Arche \& Florence Myles. 2011. Testing the predictions of the Feature Assembly Hypothesis: Evidence from the L2 acquisition of Spanish aspect morphology. In Nick Danis, Kate Mesh \& Hyunsuk Sung (eds.), Proceedings of the $35^{\text {th }}$ annual Boston University Conference on Language Development [BUCLD 35], 183-196. Somerville, MA: Cascadilla Press.

Eckman, Fred R. 1994. Local and long-distance anaphora in second-language acquisition. In Elaine E. Tarone, Susan M. Gass \& Andrew D. Cohen (eds.), Research methodology in second-language acquisition, 207-225. Hillsdale: Erlbaum.

Epstein, Samuel, Erich M. Groat, Ruriko Kawashima \& Hisatsugu Kitahara. 1998. A derivational approach to syntactic relations. Oxford: Oxford University Press.

Faltz, Leonard. 1977. Reflexivization: A study in universal syntax. Berkley, CA: University of California dissertation.

Finer, Daniel L. 1991. Binding parameters in second language acquisition. In Lynn Eubank (ed.), Point counterpoint: Universal Grammar in the second language, 351-374. Amsterdam: John Benjamins.

Finer, Daniel L. \& Ellen I. Broselow. 1986. Second language acquisition of reflexive binding. Proceedings of the North Eastern Linguistic Society 16. 154-168.

Freidin, Robert. 1997. Binding theory on minimalist assumptions. In Hans Bennis, Pierre Pica \& Johan Rooryck (eds.), Perspectives on binding and atomism, 141-153. Dordrecht: Foris.

Fukui, Naoki. 1984. Studies in Japanese anaphora. Ms. University of Massachusetts, Amherst. Gallego, Ángel J. 2010. Binding through Agree. Linguistic Analysis 34 (3-4). 163-192. 
Gallego, Ángel J. 2011. Parameters. In Cedric Boeckx (ed.), The Oxford handbook of linguistic minimalism, 523-550. Oxford: Oxford University Press.

Gil, Kook-Hee. 1998. Topic and binding in Korean. Proceedings of the University of Edinburgh Post-Graduate Conference. 1-12.

Gil, Kook-Hee. 2000. A Formal approach to long-distance anaphora: The case of Korean. Edinburgh: University of Edinburgh dissertation.

Hamilton, Robert. 1998. Underdetermined binding of reflexives by adult Japanese-speaking learners of English. Second Language Research 14 (3). 292-320.

Han, Chung-hye \& Dennis R. Storoshenko. 2009. A bound-variable analysis of the Korean anaphor caki: Evidence from corpus. Current Issues in Unity and Diversity of Languages: Collection of the Papers Selected from the 18th International Congress of Linguistics. The Linguistic Society of Korea.

Heinat, Fredrik. 2008. Probes, pronouns and binding in the minimalist program. Saarbrücken: VDM Verlag.

Hicks, Glyn. 2009. The derivation of anaphoric relations. Amsterdam: John Benjamins.

Hirakawa, Makiko. 1990. A study of the L2 acquisition of English reflexives. Second language Research 6 (1). 60-85.

Hornstein, Norbert. 2001. Move! A minimalist theory of construal. Oxford: Blackwell.

Hornstein, Norbert. 2006. Pronouns in a minimalist setting. University of Maryland Working Papers in Linguistics 14. 47-80.

Huang, C.-T. James. 1983. A note on the binding theory. Linguistic Inquiry 14. 554-561.

Huang, C.-T. James \& C.-C. Jane Tang. 1991. The local nature of long distance reflexive in Chinese. In Jan Koster \& Eric Reuland (eds.), Long distance anaphora, 263-282. Cambridge: Cambridge University Press.

Ionin, Tania. 2011. Formal theory-based methodologies. In Alison Mackey \& Susan M. Gass (eds.), Research methods in second language acquisition: A practical guide, 30-52. Oxford: Blackwell. 
Jiang, Lin. 2009. A referential/quantified asymmetry in the second language acquisition of English reflexives by Chinese-speaking learners. Second language Research 25 (4). 469-491.

Katada, Fusa. 1991. The LF representation of anaphors. Linguistic Inquiry 22(2). 287-313.

Kayne, Richard S. 2002. Pronouns and their antecedents. In Samuel D. Epstein \& T. Daniel Seely (eds.), Derivation and explanation in the minimalist program, 133-166. Oxford: Blackwell

Koster, Jan \& Eric Reuland (eds.) 1991. Long-distance anaphora. Cambridge: Cambridge University Press.

Lakshmanan, Usha \& Keiko Teranishi. 1994. Preferences versus grammaticality judgments: Some methodological issues concerning the governing category parameter in secondlanguage acquisition. In Elaine E. Tarone, Susan M. Gass \& Andrew D. Cohen (eds.), Research methodology in second-language acquisition, 185-206. Hillsdale: Erlbaum.

Lardiere, Donna. 2008. Feature assembly in second language acquisition. In Juana Liceras, Helmut Zobl \& Helen Goodluck (eds.), The role of formal features in second language acquisition, 106-140. Mahwah, NJ: Lawrence Erlbaum.

Lardiere, Donna. 2009. Some thoughts on the contrastive analysis of features in second language acquisition. Second Language Research 25 (2). 173-227.

Lebeaux, David. 1983. A distributional difference between reciprocals and reflexives. Linguistic Inquiry 14. 723-730.

Lee, Gunsoo. 2001. A minimalist account of long-distance anaphor Kucasin. Studies in Generative Grammar 11(2). 383-404.

Lee-Schoenfeld, Vera. 2004. Binding by phase: (Non-)complementarity in German. Journal of Germanic Linguistics 16(2). 111-173.

MacLaughlin, Dawn. 1998. The acquisition of the morphosyntax of English reflexives by non-native speakers. In Maria-Luise Beck (ed.), Morphology and its interfaces in second language knowledge, 195-226. Amsterdam: John Benjamins. 
Macmillan Publishers Limited. Straightforward quick placement and diagnostic test. http://www.macmillanenglish.com/straightforward/placement_tests.htm (22 February, 2010.)

Manzini, M. Rita \& Kenneth Wexler. 1987. Parameters, binding theory, and learnability. Linguistic Inquiry 18 (3). 413-444.

Matsumura, Masanori. 1994. Japanese learners' acquisition of the locality requirement of English reflexives. Studies in Second Language Acquisition 16. 19-42.

Pica, Pierre. 1987. On the nature of the reflexivization cycle. In Joyce. McDonough \& Bernadette Plunkett (eds.), Proceedings of the North Eastern Linguistics Society, 483500. University of Massachusetts, Amherst: GLSA.

Pica, Pierre. 1991. On the interaction between antecedent-government and binding: The case of long-distance reflexivization. In Jan Koster \& Eric Reuland (eds.), Long-distance anaphora, 119-135. Cambridge: Cambridge University Press.

Pollard, Carl \& Ivan Sag. 1992. Anaphors in English and the scope of binding theory. Linguistic Inquiry 23. 261-303.

Quicoli, A. Carlos. 2008. Anaphora by phase. Syntax 11(3). 299-329.

Reinhart, Tanya \& Eric Reuland. 1991. Anaphors and logophors: An argument structure perspective. In Jan Koster \& Eric Reuland (eds.), Long-distance anaphora, 283-321. Cambridge: Cambridge University Press.

Reinhart, Tanya \& Eric Reuland. 1993. Reflexivity. Linguistic Inquiry 24. 657-720.

Reuland, Eric. 2001. Primitives of binding. Linguistic Inquiry 32. 439-492.

Reuland, Eric. 2005. Binding conditions: How are they derived? In Stefan Müller (ed.), The Proceedings of the 12th International Conference on Head-Driven Phrase Structure Grammar, 578-593. Stanford, CA: CLSI Publications.

Reuland, Eric. 2011. Anaphora and language design. Cambridge, MA: MIT Press.

Schmitt, Cristina \& Karen Miller. 2010. Using comprehension methods in language acquisition research. In Elma Blom \& Sharon Unsworth (eds.), Experimental methods in language acquisition research, 35-56. Amsterdam: John Benjamins. 
Schwartz, Bonnie D. \& Rex A. Sprouse. 1994. Word order and nominative case in nonnative language acquisition: A longitudinal study of (L1 Turkish) German interlanguage. In Teun Hoekstra \& Bonnie D. Schwartz (eds.), Language acquisition studies in generative grammar, 317-368. Amsterdam: John Benjamins.

Schwartz, Bonnie D. \& Rex A. Sprouse. 1996. L2 cognitive states and the full transfer/full access model. Second Language Research 12. 40-72.

Sohng, Hong-Ki. 2004. A minimalist analysis of $\mathrm{X}^{0}$ reflexivization in Chinese and Korean. Studies in Generative Grammar 14 (3). 375-396.

Thomas, Margaret. 1989. The interpretation of English reflexive pronouns by non-native Speakers. Studies in Second Language Acquisition 11. 281-303.

Thomas, Margaret. 1991. Universal Grammar and the interpretation of reflexives in a second language. Language 67 (2). 211-239.

Thomas, Margaret. 1993. Knowledge of reflexives in a second language. Amsterdam: John Benjamins.

Thomas, Margaret. 1995. Acquisition of the Japanese reflexive zibun and movement of anaphors in logical form. Second Language Research 11 (3). 206-234.

Tsoulas, George. 2004. On a binding-theoretic argument for base generation of long distance scrambling. York Papers in Linguistics (series 2) 1. 223-236.

Ueda, Masanobu. 1984. On a Japanese reflexive zibun: A non-parameterization approach. Ms. University of Massachusetts, Amherst.

Wakabayashi, Shigenori. 1996. The nature of interlanguage: SLA of English reflexives. Second Language Research 12 (3). 266-303.

van der Weert, Cécile F. 2002. Nature or nurture: structured information knowledge. Reading Working Papers in Linguistics 6. 119-132.

White, Lydia. 1989. Universal Grammar and second language acquisition. Amsterdam: John Benjamins.

White, Lydia. 1995. Input, triggers and second language acquisition: Can binding be taught? In Fred R. Eckman, Diane Highland, Peter W. Lee, Jean. Milcham \& Rita R. Weber 
(eds.), Second language acquisition theory and pedagogy, 63-78. Mahwah, NJ: Lawrence Erlbaum.

White, Lydia. 2003. Second language acquisition and Universal Grammar. Cambridge: Cambridge University Press.

White, Lydia, Joyce Bruhn-Garavito, Takako Kawasaki, Joe Pater \& Philippe Prévost. 1997. The researcher gave the subject a test about himself: Problems of ambiguity and preference in the investigation of reflexive binding. Language Learning 47 (1). 145-172.

Ying, H. G. 1999. Access to UG and language transfer: a study of L2 learners' interpretation of reconstruction in Chinese. Second Language Research 15 (1). 41-72.

Yip, Virginia \& Gladys Tang. 1998. Acquisition of English reflexive binding by Cantonese learners. In Maria-Luise Beck (ed.), Morphology and its interfaces in second language knowledge, 165-193. Amsterdam: John Benjamins.

Yuan, Boping. 1998. Interpretation of binding and orientation of the Chinese reflexive ziji by English and Japanese speakers. Second Language Research 14 (4). 324- 340.

Zwart, Jan-Wouter. 2002. Issues relating to a derivational theory of binding. In Samuel D. Epstein \& T. Daniel Seely (eds.), Derivation and explanation in the minimalist program, 269-304. Oxford: Blackwell. 


\section{Appendix}

Note: The shaded cells indicate expected 'correct' responses.

\begin{tabular}{|c|c|c|c|c|c|}
\hline \multirow[t]{2}{*}{ Sentence Type } & \multirow[t]{2}{*}{ Options } & $\begin{array}{l}\text { Low-inter. } \\
\qquad(\mathrm{n}=19)\end{array}$ & $\begin{array}{l}\text { Intermediate } \\
\qquad(\mathrm{n}=26)\end{array}$ & $\begin{array}{l}\text { Advanced } \\
\qquad(\mathrm{n}=25)\end{array}$ & $\begin{array}{c}\text { English } \\
\text { controls } \\
(n=20)\end{array}$ \\
\hline & & $\%$ & $\%$ & $\%$ & $\%$ \\
\hline \multirow{3}{*}{$\begin{array}{l}\text { Type 1 } \\
(\mathrm{n}=5) \\
\text { locality, finite } \\
\text { clauses }\end{array}$} & LD & 7.37 & 2.31 & 0.80 & 0.00 \\
\hline & local & 88.42 & 94.62 & 98.40 & 100.00 \\
\hline & LD/local & 4.21 & 3.08 & 0.80 & 0.00 \\
\hline \multirow{3}{*}{$\begin{array}{l}\text { Type } 2 \\
(\mathrm{n}=5) \\
\text { locality, non- } \\
\text { finite clauses }\end{array}$} & $\mathrm{LD}$ & 26.32 & 17.69 & 4.80 & 1.00 \\
\hline & local & 71.58 & 79.23 & 93.60 & 99.00 \\
\hline & LD/local & 2.11 & 3.08 & 1.60 & 0.00 \\
\hline \multirow{3}{*}{ 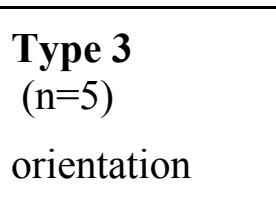 } & subject & 72.63 & 75.38 & 75.20 & 50.00 \\
\hline & object & 23.16 & 16.92 & 19.20 & 5.00 \\
\hline & sub/obj & 4.21 & 7.69 & 5.60 & 45.00 \\
\hline \multirow{3}{*}{$\begin{array}{l}\text { Type } 4 \\
(n=5) \\
\text { fillers }\end{array}$} & LD & 83.16 & 81.53 & 88.00 & 96.00 \\
\hline & local & 10.53 & 13.08 & 9.60 & 4.00 \\
\hline & LD/local & 6.32 & 5.39 & 2.40 & 0.00 \\
\hline
\end{tabular}

Table 1. Percentages of responses for the experimental and control groups 


\begin{tabular}{|c|c|c|c|c|c|}
\hline \multirow{2}{*}{$\begin{array}{c}\text { Subjects } \\
(n=19)\end{array}$} & \multicolumn{2}{|c|}{ Local binding in locality (\%) } & \multicolumn{3}{|c|}{ Orientation (Type 3, \%) } \\
\hline & $\begin{array}{c}\text { Finite } \\
\text { (Type 1) }\end{array}$ & $\begin{array}{l}\text { Non-Finite } \\
\text { (Type 2) }\end{array}$ & $\begin{array}{l}\text { Subject } \\
\text { binding }\end{array}$ & $\begin{array}{c}\text { Object } \\
\text { binding }\end{array}$ & $\begin{array}{l}\text { Sub/Obj } \\
\text { binding }\end{array}$ \\
\hline 1 & 100 & 60 & 100 & 0 & 0 \\
\hline 2 & 80 & 60 & 80 & 20 & 0 \\
\hline 3 & 100 & 100 & 80 & 20 & 0 \\
\hline 4 & 100 & 100 & 100 & 0 & 0 \\
\hline 5 & 100 & 100 & 80 & 20 & 0 \\
\hline 6 & 100 & 80 & 40 & 40 & 20 \\
\hline 7 & 100 & 40 & 80 & 20 & 0 \\
\hline 8 & 100 & 60 & 60 & 40 & 0 \\
\hline 9 & 100 & 100 & 0 & 100 & 0 \\
\hline 10 & 100 & 100 & 60 & 40 & 0 \\
\hline 11 & 60 & 80 & 60 & 20 & 20 \\
\hline 12 & 60 & 100 & 60 & 0 & 40 \\
\hline 13 & 100 & 80 & 80 & 20 & 0 \\
\hline 14 & 80 & 60 & 100 & 0 & 0 \\
\hline 15 & 60 & 40 & 60 & 40 & 0 \\
\hline 16 & 60 & 60 & 80 & 20 & 0 \\
\hline 17 & 100 & 0 & 100 & 0 & 0 \\
\hline 18 & 100 & 100 & 80 & 20 & 0 \\
\hline 19 & 80 & 40 & 80 & 20 & 0 \\
\hline
\end{tabular}

Table 2. Percentage of target responses for locality and orientation for each low-intermediate learner 


\begin{tabular}{|c|c|c|c|c|c|}
\hline \multirow{2}{*}{$\begin{array}{c}\text { Subjects } \\
(n=26)\end{array}$} & \multicolumn{2}{|c|}{ Local binding in locality (\%) } & \multicolumn{3}{|c|}{ Orientation (Type 3, \%) } \\
\hline & $\begin{array}{c}\text { Finite } \\
\text { (Type 1) }\end{array}$ & $\begin{array}{c}\text { Non-Finite } \\
\text { (Type 2) }\end{array}$ & $\begin{array}{l}\text { Subject } \\
\text { binding }\end{array}$ & $\begin{array}{c}\text { Object } \\
\text { binding }\end{array}$ & $\begin{array}{l}\text { Sub/Obj } \\
\text { binding }\end{array}$ \\
\hline 1 & 80 & 100 & 100 & 0 & 0 \\
\hline 2 & 100 & 100 & 60 & 40 & 0 \\
\hline 3 & 80 & 60 & 60 & 20 & 20 \\
\hline 4 & 100 & 80 & 100 & 0 & 0 \\
\hline 5 & 100 & 60 & 80 & 20 & 0 \\
\hline 6 & 100 & 20 & 80 & 20 & 0 \\
\hline 7 & 100 & 100 & 100 & 0 & 0 \\
\hline 8 & 100 & 100 & 60 & 20 & 20 \\
\hline 9 & 100 & 60 & 80 & 20 & 0 \\
\hline 10 & 40 & 60 & 60 & 0 & 40 \\
\hline 11 & 100 & 100 & 40 & 40 & 20 \\
\hline 12 & 100 & 100 & 60 & 0 & 40 \\
\hline 13 & 100 & 100 & 80 & 20 & 0 \\
\hline 14 & 100 & 100 & 40 & 20 & 40 \\
\hline 15 & 100 & 60 & 80 & 20 & 0 \\
\hline 16 & 100 & 60 & 80 & 20 & 0 \\
\hline 17 & 100 & 100 & 80 & 20 & 0 \\
\hline 18 & 100 & 100 & 100 & 0 & 0 \\
\hline 19 & 100 & 100 & 80 & 20 & 0 \\
\hline 20 & 100 & 100 & 80 & 20 & 0 \\
\hline 21 & 100 & 60 & 60 & 40 & 0 \\
\hline 22 & 80 & 100 & 80 & 20 & 0 \\
\hline 23 & 100 & 60 & 60 & 20 & 20 \\
\hline 24 & 100 & 20 & 80 & 20 & 0 \\
\hline 25 & 80 & 100 & 80 & 20 & 0 \\
\hline 26 & 100 & 60 & 100 & 0 & 0 \\
\hline
\end{tabular}

Table 3. Percentage of target responses for locality and orientation for each intermediate learner 


\begin{tabular}{|c|c|c|c|c|c|}
\hline \multirow{2}{*}{$\begin{array}{c}\text { Subjects } \\
(n=25)\end{array}$} & \multicolumn{2}{|c|}{ Local binding in locality (\%) } & \multicolumn{3}{|c|}{ Orientation (Type 3, \%) } \\
\hline & $\begin{array}{c}\text { Finite } \\
\text { (Type 1) }\end{array}$ & $\begin{array}{c}\text { Non-Finite } \\
\text { (Type 2) }\end{array}$ & $\begin{array}{l}\text { Subject } \\
\text { binding }\end{array}$ & $\begin{array}{r}\text { Object } \\
\text { binding }\end{array}$ & $\begin{array}{l}\mathrm{Sub} / \mathrm{Ob} \\
\text { binding }\end{array}$ \\
\hline 1 & 100 & 100 & 60 & 40 & 0 \\
\hline 2 & 80 & 80 & 60 & 20 & 20 \\
\hline 3 & 100 & 80 & 20 & 40 & 40 \\
\hline 4 & 100 & 100 & 80 & 20 & 0 \\
\hline 5 & 100 & 100 & 100 & 0 & 0 \\
\hline 6 & 100 & 100 & 80 & 20 & 0 \\
\hline 7 & 100 & 100 & 60 & 40 & 0 \\
\hline 8 & 100 & 100 & 40 & 60 & 0 \\
\hline 9 & 100 & 80 & 100 & 0 & 0 \\
\hline 10 & 100 & 100 & 80 & 0 & 20 \\
\hline 11 & 100 & 100 & 100 & 0 & 0 \\
\hline 12 & 100 & 100 & 80 & 20 & 0 \\
\hline 13 & 100 & 80 & 80 & 20 & 0 \\
\hline 14 & 100 & 100 & 80 & 20 & 0 \\
\hline 15 & 100 & 80 & 80 & 20 & 0 \\
\hline 16 & 100 & 80 & 100 & 0 & 0 \\
\hline 17 & 100 & 100 & 20 & 40 & 40 \\
\hline 18 & 100 & 100 & 80 & 20 & 0 \\
\hline 19 & 100 & 100 & 80 & 20 & 0 \\
\hline 20 & 100 & 100 & 100 & 0 & 0 \\
\hline 21 & 80 & 80 & 60 & 40 & 0 \\
\hline 22 & 100 & 80 & 100 & 0 & 0 \\
\hline 23 & 100 & 100 & 100 & 0 & 0 \\
\hline 24 & 100 & 100 & 60 & 20 & 20 \\
\hline 25 & 100 & 100 & 80 & 20 & 0 \\
\hline
\end{tabular}

Table 4. Percentage of target responses for locality and orientation for each advanced learner 